\title{
P-gp expression inhibition mediates placental glucocorticoid barrier opening and fetal weight loss
}

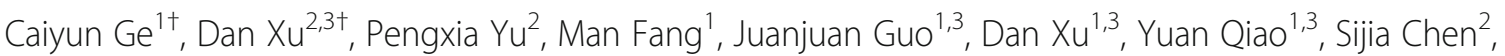
Yuanzhen Zhang ${ }^{1,3^{*}}$ and Hui Wang ${ }^{1,2,3^{*}}$ (D)

\begin{abstract}
Background: Prenatal adverse environments can cause fetal intrauterine growth retardation (IUGR) and higher susceptibility to multiple diseases after birth, related to multi-organ development programming changes mediated by intrauterine overexposure to maternal glucocorticoids. As a glucocorticoid barrier, P-glycoprotein (P-gp) is highly expressed in placental syncytiotrophoblasts; however, the effect of P-gp on the occurrence of IUGR remains unclear.

Methods: Human placenta and fetal cord blood samples of IUGR fetuses were collected, and the related indexes were detected. Pregnant Wistar rats were administered with $30 \mathrm{mg} / \mathrm{kg} \cdot \mathrm{d}$ (low dose) and $120 \mathrm{mg} / \mathrm{kg} \cdot \mathrm{d}$ (high dose) caffeine from gestational day (GD) 9 to 20 to construct the rat IUGR model. Pregnant mice were administered with caffeine $(120 \mathrm{mg} / \mathrm{kg} \cdot \mathrm{d})$ separately or combined with sodium ferulate $(50 \mathrm{mg} / \mathrm{kg} \cdot \mathrm{d})$ from gestational day GD 9 to 18 to confirm the intervention target on fetal weight loss caused by prenatal caffeine exposure (PCE). The fetal serum/ placental corticosterone level, placental P-gp expression, and related indicator changes were analyzed. In vitro, primary human trophoblasts and BeWo cells were used to confirm the effect of caffeine on P-gp and its mechanism.
\end{abstract}

\footnotetext{
* Correspondence: wanghui19@whu.edu.cn; zhangyuanzhen@vip.sina.com

${ }^{\dagger}$ Caiyun Ge and Dan Xu contributed equally to this work.

${ }^{1}$ Department of Obstetrics and Gynaecology, Zhongnan Hospital of Wuhan University, 169 Donghu Road, Wuchang District, Wuhan 430071, China

Full list of author information is available at the end of the article
}

(c) The Author(s). 2021 Open Access This article is licensed under a Creative Commons Attribution 4.0 International License, which permits use, sharing, adaptation, distribution and reproduction in any medium or format, as long as you give appropriate credit to the original author(s) and the source, provide a link to the Creative Commons licence, and indicate if changes were made. The images or other third party material in this article are included in the article's Creative Commons licence, unless indicated otherwise in a credit line to the material. If material is not included in the article's Creative Commons licence and your intended use is not permitted by statutory regulation or exceeds the permitted use, you will need to obtain permission directly from the copyright holder. To view a copy of this licence, visit http://creativecommons.org/licenses/by/4.0/ The Creative Commons Public Domain Dedication waiver (http://creativecommons.org/publicdomain/zero/1.0/) applies to the data made available in this article, unless otherwise stated in a credit line to the data. 
Results: The placental P-gp expression was significantly reduced, but the umbilical cord blood cortisol level was increased in clinical samples of the IUGR neonates, which were positively and negatively correlated with the neonatal birth weight, respectively. Meanwhile, in the PCE-induced IUGR rat model, the placental P-gp expression of IUGR rats was decreased while the corticosterone levels of the placentas/fetal blood were increased, which were positively and negatively correlated with the decreased placental/fetal weights, respectively. Combined with the PCE-induced IUGR rat model, in vitro caffeine-treated placental trophoblasts, we confirmed that caffeine decreased the histone acetylation and expression of P-gp via RYR/JNK/YB-1/P300 pathway, which inhibited placental and fetal development. We further demonstrated that P-gp inducer sodium ferulate could reverse the inhibitory effect of caffeine on the fetal body/placental weight. Finally, clinical specimens and other animal models of IUGR also confirmed that the JNK/YB-1 pathway is a co-regulatory mechanism of P-gp expression inhibition, among which the expression of YB-1 is the most stable. Therefore, we proposed that YB-1 could be used as the potential early warning target for the opening of the placental glucocorticoid barrier, the occurrence of IUGR, and the susceptibility of a variety of diseases.

Conclusions: This study, for the first time, clarified the critical role and epigenetic regulation mechanism of P-gp in mediating the opening mechanism of the placental glucocorticoid barrier, providing a novel idea for exploring the early warning, prevention, and treatment strategies of IUGR.

Keywords: Intrauterine growth retardation, P-glycoprotein, Placental glucocorticoid barrier, Prenatal caffeine exposure, Histone acetylation

\section{Background}

Intrauterine growth retardation (IUGR) refers to a fetus that grew slowly in the uterus and failed to achieve the expected weight for gestational age [1]. IUGR usually results in growth retardation, multiple organ dysfunction, and low birth weight, which can cause fetal distress, neonatal asphyxia, and even perinatal death $[2,3]$. The epidemiological survey has shown that the incidence of IUGR was about 3-9\% in socioeconomically developed areas, while it was as high as $30 \%$ in economically underdeveloped areas [4]. Children with IUGR, especially those who had catch-up growth during early life, have a higher risk of susceptibility to various diseases, including metabolic diseases (MS), type 2 diabetes, cardiovascular diseases, and mental diseases in later life [5-8]. Besides, animal studies have revealed that adverse environments during pregnancy (such as xenobiotics exposure and dietary restrictions, etc.) can increase the incidence of IUGR and the susceptibility to many chronic diseases after birth [9-11]. At present, there are still many difficulties in the prevention and treatment of IUGR, mainly related to the unclear mechanism of occurrence and target of intervention.

Glucocorticoids play an essential role in maintaining pregnancy and regulating embryonic tissue morphology and function maturity [12]. However, overexposure to glucocorticoids caused by various prenatal factors may be a trigger for adverse developmental outcomes (e.g., IUGR), affecting fetal developmental programming and leading to susceptibility to a variety of fetal-originated diseases in adults [13-15]. Maternal glucocorticoid levels in the fetus are mainly regulated by the placental glucocorticoid barrier, including $11 \beta$-hydroxysteroid dehydrogenase type $2(11 \beta-H S D 2)$ and P-glycoprotein (Pgp). The $11 \beta-H S D 2$ can reduce glucocorticoids from entering fetal circulation by inactivating glucocorticoids [15]. In our previous studies, through a series of animal experiments, we have established stable IUGR offspring rat models caused by prenatal xenobiotics exposure such as caffeine, nicotine, and ethanol and confirmed that prenatal xenobiotics exposure induced-IUGR was associated with a low expression level of placental 11 $\beta$-HSD2 $[10,16,17]$. P-gp is one of the most abundantly expressed proteins of the ATP binding cassette efflux transporter family in the placentas. P-gp in the placental trophoblasts can use ATP to pump glucocorticoids back to the maternal circulation [18]. However, the effect of P-gp as a placental glucocorticoid barrier on the occurrence of IUGR is unclear.

Clinical and animal studies have found that adverse environments during pregnancy can cause IUGR. Caffeine is the most widely consumed psychoactive drug in the world. According to statistics, $82 \%$ of pregnant women have been reported to consume caffeine daily in the USA [19] and 91\% in France [20]. Epidemiological investigations have proved that prenatal caffeine exposure (PCE) can cause toxic effects of reproduction and fetal development, such as the increased risk of congenital malformations, premature delivery, spontaneous abortion, IUGR, and susceptibility to chronic diseases $[21,22]$. Our animal experiments also demonstrated that PCE could not only increase maternal glucocorticoid levels but also cause fetal overexposure to glucocorticoid by inhibiting placental $11 \beta$-HSD2, leading to the 
occurrence of IUGR and susceptibility to multiple chronic diseases in adult offspring [16, 23-26]. However, whether caffeine causes IUGR by affecting placental Pgp has not been reported yet. Epigenetic changes are critical to gene regulation in the developing placenta. As an essential transporter of syncytiotrophoblast, the epigenetic regulation mechanism of placental P-gp is rarely reported. It has been suggested [27, 28] that the JNK pathway and Y-box binding protein-1 (YB-1) may be involved in P-gp regulation. It is not known whether the JNK pathway, YB-1, and epigenetic modifications are involved in the regulation of placental P-gp by caffeine.

Here, using clinical specimens and PCE-induced IUGR rat model, we first determined the glucocorticoid barrier function of placental P-gp in the IUGR neonates and fetal rats by analyzing the correlations among the placental P-gp expression levels, placental/fetal glucocorticoid levels, and placental/fetal body weights. Furthermore, by combining in vivo experiments of caffeine, the clinical IUGR samples, and rat IUGR models, we will clarify the epigenetic mechanism of P-gp expression changes in placental trophoblast cells. Next, P-gp inducer sodium ferulate will be used to confirm the intervention target on fetal weight loss caused by PCE. Finally, we will confirm the potential early warning targets of IUGR occurrence and multiple disease susceptibility using clinical specimens. This study will illuminate the underlying mechanism of IUGR from the perspective of placental P-gp and provide a novel idea for analyzing the placental origin of adult diseases, as well as the exploration of early warning targets and potential intervention strategies.

\section{Methods}

\section{Chemicals and reagents}

Caffeine (C0750) and cortisol (C46329) and DNase I (DN25) were obtained from Sigma-Aldrich Co., Ltd. (St Louis, MO, USA). Rat corticosterone ELISA kits (RE52211) and cortisol ELISA kits (RE52061) were purchased from IBL International (Germany). Dantrolene (B6329), SP600125 (A4604), and Rhodamine 123 (Rho 123, C3140) were purchased from APExBIO Technology LLC (Houston, MA, USA). Trypsin (9002-07-7) and lipofectamine 3000 (L3000015) were purchased from Gibco Co. (Detroit, MI, USA). YB-1 pcDNA3.1( + ) plasmid was constructed by GenePharma Co., Ltd. (Shanghai, China). TRIzol (15596018) reagent was purchased from Invitrogen Co. (Carlsbad, CA, USA). The quantitative real-time PCR (qRT-PCR) reverse transcription (R312) and SYBR qPCR master mix kits (Q711) were purchased from Vazyme Biotech Co., Ltd. (Nanjing, China). The nuclear and cytoplasmic protein preparation kit (P1200) and BCA assay kit (P1511) were purchased from Applygen Co., Ltd. (Beijing, China). Primary antibodies anti-P-gp (ab170904), anti-YB-1 (ab76149), anti-P300 (ab14984), anti-acetyl H3K9 (ab10812), antiacetyl H3K14 (ab52946), and IgG (ab172730) antibody were purchased from Abcam Technology Co., Ltd. (Cambridge, UK). The anti-JNK (A4867), anti-p-JNK (AP0631), anti-H3 (A2348), and anti-GAPDH (A10868) antibodies were purchased from ABclonal Technology Co., Ltd. (Wuhan, China). The enhanced chemiluminescence kit (ECL, 32209) was obtained from Pierce Biotechnology Inc. (Rockford, IL, USA). Chromatin immunoprecipitation (ChIP) assay kit (17-295) was purchased from Millipore Co., Ltd. (Billerica, MA, USA). DNA purification kit (DP214) was purchased from Tiangen Biotech Co., Ltd. (Beijing, China). The other reagents for experiments were of analytical grade.

\section{Human placental tissue collection}

The placentas from IUGR neonates were collected after obtaining informed consent from pregnant women who underwent a cesarean section or natural delivery at the Division of Gynecology and Obstetrics of Zhongnan Hospital, Wuhan University, between June 2017 and June 2018. It was approved by the Medical Ethical Committee of Zhongnan Hospital of Wuhan University (approval number 201606). IUGR was diagnosed according to an intrauterine condition when a baby's weight is below the 10th centile for gestational age [29]. The following criteria were required for the inclusion: singleton pregnancy, gestational age within 28-40 weeks, and the weight of the fetus in the control group is adapted to the gestational age, while the weight of the fetus in the IUGR group is lower than the 10th percentile of the gestational age. The fetus with any congenital genetic diseases, fetal structural, genetic, or chromosomal abnormalities was excluded. Pregnancy complications, including pre-eclampsia and gestational diabetes, are also adverse environments during pregnancy since they can cause maternal stress and HPA axis activation [30, 31], which is consistent with the research goal that we want to study the adverse environments during pregnancy leading to fetal weight loss. Therefore, women with pregnancy complications were not excluded from the IUGR group. Thirty control and 26 IUGR neonatal placentas, $89.3 \%$ of cesarean section, and $10.7 \%$ (3/30 in the control group, $3 / 26$ in the IUGR group) of natural delivery were finally recruited. The samples of the control group were collected from healthy women, and the samples of the IUGR group were collected from healthy women or women with pregnancy complications (15 cases of pre-eclampsia, 6 cases of gestational diabetes, 2 cases of nuchal cord, and 1 case of oligohydramnios). The placental tissues and umbilical cord blood were collected immediately after delivery. The placental tissue was dissected at the middle zone after the amniotic 
membranes, decidua, and connective tissues had been removed. Partial placental tissue was fixed with 10\% paraformaldehyde, and partial tissue was immediately snap-frozen in liquid nitrogen and stored at $-80^{\circ} \mathrm{C}$ after being washed thoroughly with saline. Fetal cord serum was isolated from umbilical cord blood by centrifugation.

\section{Animals and treatment}

Specific pathogen-free Wistar rats and C57BL/6 mice were obtained from the Experimental Center of Hubei Medical Scientific Academy (No. 2017-0018, certification number: 42000600002258, Hubei, China). The animal protocol of rats was reviewed and approved by the Ethics Committee of Wuhan University School of Medicine (No. 14016), and the animal protocol of mice was reviewed and approved by the Institutional Animal Care and Use Committee (IACUC) of Wuhan University Center for Animal Experiment (No. WP20210003). All the protocols were conformed to the National Institutes of Health guide for the care and use of laboratory animals.

Details of rat feeding and mating were described as before [32]. Upon confirmation of mating by the appearance of sperm in a vaginal smear, the day was defined as the gestational day (GD) 0. From GD9 to GD20, the rats in PCE groups were intragastrical administered 30 and $120 \mathrm{mg} / \mathrm{kg} \cdot \mathrm{d}$ caffeine (dissolved in distilled water) according to the $\mathrm{PCE}(\mathrm{L})$ (low dose) and $\mathrm{PCE}(\mathrm{H})$ (high dose) groups, the prenatal ethanol exposure (PEE) group was given $4 \mathrm{~g} / \mathrm{kg} \cdot \mathrm{d}$ ethanol (dissolved in distilled water) by gavage administration, while the control group was given the same volume of distilled water. Pregnant rats were injected subcutaneously with $0.8 \mathrm{mg} / \mathrm{kg} \cdot \mathrm{d}$ dexamethasone (dissolved in saline) for the prenatal dexamethasone exposure (PDE) group or saline for the control group. On GD20, pregnant rats were sacrificed after being anesthetized at $8 \mathrm{am}$. The sex of the fetal rats was judged by the anogenital distance and then was ensured by the anatomy of the testicles or ovaries. The fetal blood of the same sex in each litter was combined into a single specimen. Maternal and fetal serum was isolated from the blood by centrifugation (3500 rpm) for $15 \mathrm{~min}$. The placental tissue from three different fetal rats from each litter was randomly collected, pooled, and counted as one sample according to gender for further RNA and protein extraction according to methods previously described [33]. Partial placental tissue was fixed with $4 \%$ paraformaldehyde for immunohistochemistry assay. While the other samples were frozen immediately in liquid nitrogen, followed by storage at $-80^{\circ} \mathrm{C}$ for subsequent examination.
IUGR rate per litter $(\%)=($ number of IUGR rat fetuses per litter/the total number of fetal rats per litter $) \times 100$ IUGR rate per group $(\%)=$ (the sum of fetal rat IUGR rate per litter/each group of litter number $) \times 100$

For the intervention study of mice, the pregnant mice were randomly divided into four groups, namely the control group (control), the caffeine group (caffeine), the sodium ferulate group (sodium ferulate), and the caffeine + sodium ferulate group (caffeine + sodium ferulate). From GD9 to GD18, both caffeine $(120 \mathrm{mg} / \mathrm{kg} \cdot \mathrm{d})$ and sodium ferulate $(50 \mathrm{mg} / \mathrm{kg} \cdot \mathrm{d})$ were administered by gavage, while the control group was given the same volume of distilled water. On GD18, pregnant mice were sacrificed after anesthetized. IUGR was diagnosed when an animal's body weight was two standard deviations less than the mean body weight of the control group. The methods of the preservation and treatment of the sample in mice were similar to the previous procedure.

\section{Immunohistochemistry and immunofluorescence measurement}

Placental tissues embedded with paraffin were cut into 5 - $\mu \mathrm{m}$-thick slices along the longitudinal axis. Then, the slices were deparaffinized and rehydrated with xylene and a series of grades of alcohol and then were performed using a microwave treatment for $15 \mathrm{~min}$ in citrate buffer ( $\mathrm{pH}$ 6.0). Then, they were soaked in $3 \% \mathrm{H}_{2} \mathrm{O}_{2}$ for $25 \mathrm{~min}$ for immunochemistry or socked in Triton $\mathrm{X}$ 100 to penetrate the membrane for $30 \mathrm{~min}$ for immunofluorescence. The antigen retrieval sections were then blocked with $10 \%$ goat serum at $37^{\circ} \mathrm{C}$ for $30 \mathrm{~min}$ and incubated with a primary anti-P-gp (1:200) or anti-YB-1 (1:150) antibody overnight at $4^{\circ} \mathrm{C}$, following by incubation with the secondary antibody at $37^{\circ} \mathrm{C}$ for $50 \mathrm{~min}$. Slides were stained with $\mathrm{DAB}$ and counterstained with hematoxylin for immunochemistry or dyed with DAPI for immunofluorescence. The mean of integrated optic density (IOD) was measured in 6 different fields for each sample, 5 different samples of each group using ImagePro Plus (version 6.1, Media Cybernetics, Silver Spring, MD, USA).

\section{Isolation of villous trophoblasts}

A method of modified Kliman [34] and Zhang [35] was used for placental trophoblasts isolation and purification. Briefly, the tissue removed from the mother's side of the placenta was minced after washing with normal saline and was digested with $0.125 \%$ trypsin and $0.03 \%$ DNase I four times (20, 20, 15, $10 \mathrm{~min})$, followed by digestion termination with $10 \%$ fetal bovine serum. Purified trophoblast cells could be obtained by screening with nylon net $(40 \mu \mathrm{m})$ after isolation using a 5-65\% Percoll. Collected trophoblasts were seeded with a density at $2 \times 10^{6}$ cells were inserted into 6 -well plates. 


\section{Cell culture and treatment}

The BeWo cell line is derived from human placental villous carcinoma, which was purchased from the China Center for Type Culture Collection (Wuhan, China). The BeWo cells or placental trophoblasts were cultured in modified Eagle's medium supplemented with 10\% fetal bovine serum and $0.1 \%$ penicillin/streptomycin at $37^{\circ} \mathrm{C}$ in a $5 \% \mathrm{CO}_{2}$ humidified incubator. The cells were treated with different concentrations of caffeine $(0,0.1$, $1,10$, and $10 \mu \mathrm{M})$ for $48 \mathrm{~h}$ to test the effect of caffeine on P-gp expression.

To confirm the signaling pathway, nonspecific and competitive ryanodine receptor (RYR) antagonist (dantrolene), JNK inhibitor (SP600125), and YB-1 overexpression plasmid were used. Briefly, the BeWo cells were plated at a density of $4 \times 10^{5}$ cells per well in 6-well plates, after reaching $30-50 \%$ confluent, dantrolene $(10$ $\mu \mathrm{M})$, and SP600125 $(10 \mu \mathrm{M})$ were added to the cells, respectively. As to the overexpression of YB-1, after being cultured in 6-well plates, BeWo cells were transfected with the plasmid $1 \mu \mathrm{g}$ per well using Lipofectamine 3000 according to the manufacturer's protocols. After $48 \mathrm{~h}$ transfection, the cells were harvested for the subsequent analysis.

\section{P-gp activity measurement}

After incubation with caffeine for $48 \mathrm{~h}$ in a 96-well plate, the BeWo cells were washed by $\mathrm{PBS}\left(37^{\circ} \mathrm{C}\right) 3$ times and then treated with $10 \mu \mathrm{M}$ Rho 123 for $1.5 \mathrm{~h}$. To detect the accumulation of Rho 123, cells were perforated with $1 \%$ Triton X-100 for 10 min after being washed with cold PBS. The fluorescence of Rho 123 accumulation was measured with a fluorescence plate reader (Molecular Devices, Wokingham, UK) (excitation/emission wavelength: $485 \mathrm{~nm} / 530 \mathrm{~nm}$ ).

\section{Transport experiment}

The BeWo cells were transferred to transwell ${ }^{\circ}$ polycarbonate membranes (12-mm diameter, $0.4-\mu \mathrm{m}$ pore size). The cells were plated at a density of $1 \times 10^{5}$ cells $/ \mathrm{cm}^{2}$ with a certain volume of medium in the apical and basal chambers, and the medium was replaced daily. The cells were cultured with different concentrations of caffeine for $48 \mathrm{~h}$. On day 6 of post-seeding, the confluent monolayer was formed according to the study's findings [36]. $200 \mathrm{nM}$ cortisol was added to the apical chamber, and the transwell was incubated at $37^{\circ} \mathrm{C}$ for $120 \mathrm{~min}$. Then, a sample of $0.2 \mathrm{ml}$ was taken from the basolateral compartment for cortisol measurement.

\section{Serum, placenta, and cell culture fluid corticosterone/ cortisol measurement}

Placental tissues were homogenized with $1 \mathrm{ml}$ PBS, then centrifuged at $12000 \times g$ at $4^{\circ} \mathrm{C}$ for $5 \mathrm{~min}$. The levels of rats/mice serum and placental corticosterone were detected by an ELISA kit following the manufacturer's introductions. The minimum detection of the corticosterone is $0.56 \mathrm{ng} / \mathrm{mL}$. The intra-assay and interassay coefficients of variation were $4 \%$ and $5.5 \%$. The cortisol levels of the human placenta and cell culture were tested using the ELISA kit.

\section{Total RNA extract and qRT-PCR}

The total RNA was isolated using TRIzol reagent. Then, $1 \mu \mathrm{g}$ of purified RNA was reverse-transcribed into cDNA using the qRT-PCR reverse kit according to the supplier's instructions. The relative mRNA level of ABCB1 (ATP binding cassette subfamily B member 1), RYRs, and P300 was detected by an SYBR qPCR master mix kit. GAPDH was selected for rat and human and ubiquitin $C$ (UBC) was selected for mouse as the housekeeping gene, and the relative expression levels of these genes were calculated using the $2^{-\Delta \Delta C t}$ method. The sequences of primers for each gene are shown in Table 1. All oligonucleotide primers were synthesized by Sangon Biotech Co., Ltd. (Shanghai, China).

\section{Chromatin immunoprecipitation (ChIP) and re-ChIP assays} To analyze binding levels of YB-1, P300, H3K9ac, and $\mathrm{H} 3 \mathrm{~K} 14 \mathrm{ac}$ at the promoter region of the $\mathrm{ABCB} 1$ gene, we performed ChIP assays according to the manufacturer's procedures. The samples were resuspended in $0.5 \mathrm{ml}$ lysis buffer containing protease inhibitors and then sonicated. $10 \mu \mathrm{L}$ lysis buffer of the samples was used for input DNA, and the left lysis buffer was incubated with Protein A/G beads used for immunoprecipitation with 1 $\mu \mathrm{g}$ anti-YB-1, anti-P300, anti-acetyl H3K9, anti-acetyl $\mathrm{H} 3 \mathrm{~K} 14$, and IgG antibody at $4^{\circ} \mathrm{C}$ overnight, followed by incubation with BSA-treated Proteinase $\mathrm{K}$ at $65^{\circ} \mathrm{C}$ for 8 h. For re-ChIP, an anti-YB-1 antibody was used for primary IP, followed by anti-P300 for the second IP, and a nonspecific IgG antibody was used as a control. The sheared DNA recovered from cross-linking was extracted with a DNA purification kit. The DNA associated with target proteins was analyzed by quantitative PCR to quantify the amount of ABCB1 DNA associated with these marks. Data were obtained by normalizing $2^{-\Delta \Delta C t}$ from qRT-PCR. ChIP primers spanning the $\mathrm{ABCB} 1$ binding region used are as follows: Human (ABCB1): TGTAGCTGGTTGGTTGGGAT and CTGG CCTTGTGACTTGCTTT (histone acetylation); TCTCGAGGAATCAGCATTCA and AAGAGCCGCT ACTCGAATGA (YB-1 and P300); Rat (abcb1a): TTATGAAGTGTGCGGGAGTG and GGACCGTA GCGAGAACAAAT (histone acetylation); Rat (abcb1b): GGAGCGCCATGTAAAATGCA and CGTAGCGAGA ACAAATGCCA (histone acetylation). 
Table 1 Oligonucleotide primers in quantitative real-time PCR

\begin{tabular}{|c|c|c|c|}
\hline Gene & Forward primer & Reverse primer & Locus \\
\hline \multicolumn{4}{|l|}{ Rat } \\
\hline abcb1a & TAGCAGGAGTGGTTGAAATG & CAAGCTCTGGGCATACATAG & NM_133401.2 \\
\hline abcb1b & CATCCAGAACGCAGACTTGA & CAGCCTGAACCATCGAGAAA & NM_012623.3 \\
\hline RYR1 & CATCCTITCATCCGTCACTC & TCATCTTCGCTCTTGTTGTAG & XM_039100851.1 \\
\hline RYR2 & AGGGAGAGAGGAAGCCATTA & GGTCACTGAGACCAGCATTT & XM_039096071.1 \\
\hline RYR3 & CACTGACAACTCCTITCTCTAC & GGATCGTCCTCAAGGTCTTA & XM_039106806.1 \\
\hline GAPDH & GCAAGTTCAACGGCACAG & GCCAGTAGACTCCACGACA & NM_017008.4 \\
\hline \multicolumn{4}{|l|}{ Mouse } \\
\hline abcb1a & CAGCCAGCATTCTCCGTAATA & GTGAGGATCTCTCCAGCTTTG & NM_011076.3 \\
\hline abcb1b & TCCCTGTTCTTTCTGGTTATGG & CCCGAGGTTTGCTACATTCT & NM_011075.2 \\
\hline UBC & AGGTGGGATGCAGATCTTTG & ССTCCTTGTCCTGGATCTTTG & NM_019639.4 \\
\hline \multicolumn{4}{|l|}{ Human } \\
\hline $\mathrm{ABCB} 1$ & GGTGGTGTCACAGGAAGAGATT & TCTAACAAGGGCACGAGCTATG & NM_001348945.2 \\
\hline RYR1 & GCTCCCTGTGTGTGTGTAAT & CGGATGCTGGTGACATAGTT & NM_000540.3 \\
\hline RYR2 & GAGATGGTCCCTCACCAAATAG & CGTCCCAAGAGGTCAATCAA & NM_001035.3 \\
\hline RYR3 & GGAGAAGGTCAGCATAGACAAG & TCCAGTCACCACTTCAAACTC & NM_001036.6 \\
\hline YB-1 & GCAGCAGACCGTAACCATTAT & TCTCCGATCCCTCGTTCTTT & NM_004559.5 \\
\hline P300 & CCAGCCATGCAGAACATGAA & CGGAATTGTGAAGGCATGGT & NM_001429.4 \\
\hline GAPDH & GAAATCCCATCACCATCTTCCAG & ATGAGTCCTTCCACGATACCAAAG & NM_002046.7 \\
\hline
\end{tabular}

Protein extract, Western blotting, and coimmunoprecipitation assays

Homogenate tissues or cells were lysed in RIPA buffer containing 1\% Protease Inhibitor Cocktail. For the nuclear and cytoplasm protein fractionation, a nuclear and cytoplasmic protein preparation kit was used following the manufacturer's protocol. The protein concentration of the samples was determined with a BCA assay kit. Equal amounts of protein were separated by SDS-polyacrylamide gel electrophoresis (SDS-PAGE) and transferred onto a PVDF microporous membrane. The membranes were blocked with $5 \%$ skim milk and then incubated with anti-P-gp (1:1000), antiYB-1 (1:1000), anti-P300 (1:1000), anti-JNK (1:1500), antip-JNK (1:1000), anti-H3 (1:5000), or anti-GAPDH (1:2000) antibody at $4{ }^{\circ} \mathrm{C}$ overnight, followed by incubation with secondary antibodies at room temperature for $1.5 \mathrm{~h}$. The blots were visualized by the ECL kit. For the immunoprecipitation assay, the protein was incubated with $1 \mu \mathrm{g}$ p-JNK or YB-1 antibody overnight. Then, $40 \mu \mathrm{l} 50 \%$ protein A/G agarose beads were added and continued for $4 \mathrm{~h}$. Beads were resuspended and boiled with $2 \times$ SDS-PAGE loading buffer for western blotting analysis.

\section{Statistical analysis}

Data were presented as mean \pm S.E.M. Statistical differences among gene expression in the placentas were calculated and plotted using Graph Pad Prism 6.0 (GraphPad Software, Inc., USA). Comparisons between 2 groups were made by two-tailed Student $t$ tests and $>2$ groups were analyzed by one-way ANOVA method. The association of different targets was analyzed using Pearson methods. For all tests, a $P<0.05$ was considered to be significantly different.

\section{Results}

Correlations among P-gp expression in the human placenta, fetal cord blood cortisol levels, and neonatal birth weights

To figure out the relationship between placental P-gp expression and fetal birth weight, we collected placental and fetal cord blood samples of clinical IUGR and the gestational age-matched control neonates. The clinical characteristics of the included patients are shown in Table 2. Compared with the control group, there was no noticeable difference in the age and gestational age of pregnant women in the IUGR group, while the body length and body weight of the neonates were significantly reduced $(P<0.01)$. Using immunohistochemical analysis, we found that P-gp was mainly expressed on maternal-facing syncytiotrophoblasts (black arrow, Fig. 1A, B). It was further found that the mRNA and protein expression levels of placental P-gp (ABCB1) were significantly reduced, and the cortisol concentrations of the placenta and fetal cord blood were increased in the IUGR group, and there was no significant difference between males and females $(P<$ 0.05, $P<0.01$, Fig. $1 \mathrm{C}-\mathrm{F})$. Additionally, the placental $\mathrm{P}$-gp 
Table 2 Clinical characteristics of neonates

\begin{tabular}{|c|c|c|c|c|}
\hline \multirow[t]{2}{*}{ Group } & \multicolumn{2}{|l|}{ Female } & \multicolumn{2}{|l|}{ Male } \\
\hline & Control $(n=9)$ & IUGR $(n=13)$ & Control $(n=21)$ & IUGR $(n=13)$ \\
\hline Maternal age & $34.0 \pm 2.7$ & $30.0 \pm 1.3$ & $32.0 \pm 1.5$ & $32.0 \pm 1.3$ \\
\hline Gestational weeks & $36.0 \pm 0.8$ & $35.0 \pm 0.7$ & $36.0 \pm 0.4$ & $35.0 \pm 0.7$ \\
\hline Neonatal birth weight (g) & $3041 \pm 159$ & $1863 \pm 128^{* *}$ & $2769 \pm 130$ & $1793 \pm 115^{*}$ \\
\hline Neonatal birth length $(\mathrm{cm})$ & $50.0 \pm 0.4$ & $42.0 \pm 1.6^{* *}$ & $48.0 \pm 0.6$ & $43.0 \pm 1.1^{* *}$ \\
\hline
\end{tabular}

IUGR intrauterine growth retardation, ${ }^{* *} P<0.01$ vs. control

protein expression levels in female and male neonates were negatively correlated with fetal cord blood cortisol levels and positively correlated with birth weights, while the fetal cord blood cortisol levels were negatively correlated with the birth weights in male and female neonates $(P<0.05, P<0.01$, Fig. $1 \mathrm{G}-\mathrm{I})$. These results suggest that placental P-gp expression was decreased, the fetal cord blood cortisol level was increased in the neonates with IUGR, and the birth weight was significantly related to placental P-gp expression and cord blood cortisol level.
Changes of fetal body/placental weights, fetal serum/ placental corticosterone levels, and P-gp expression and their relationships in PCE-induced IUGR rat model

To verify the relationship between P-gp and the occurrence of IUGR in population experiments, pregnant Wistar rats were intragastrically given 30 and $120 \mathrm{mg} / \mathrm{kg} \cdot \mathrm{d}$ caffeine during GD 9-20 to establish an in vivo IUGR model. As shown in Fig. 2, compared with the control group, the fetal body weights and placental weights of the $\operatorname{PCE}(\mathrm{L})$ and $\operatorname{PCE}(\mathrm{H})$ group were decreased, and the ratio of fetal body weights/

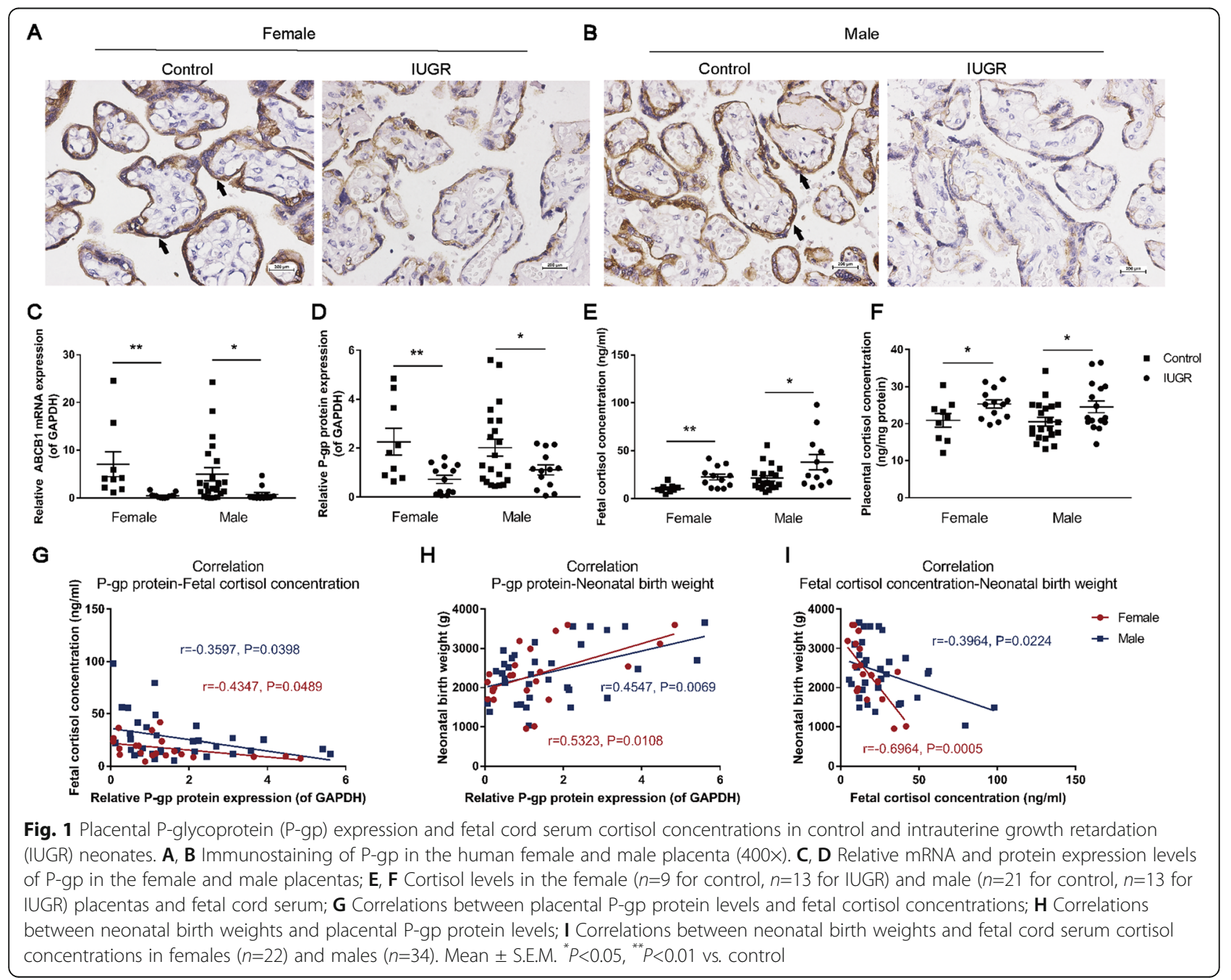



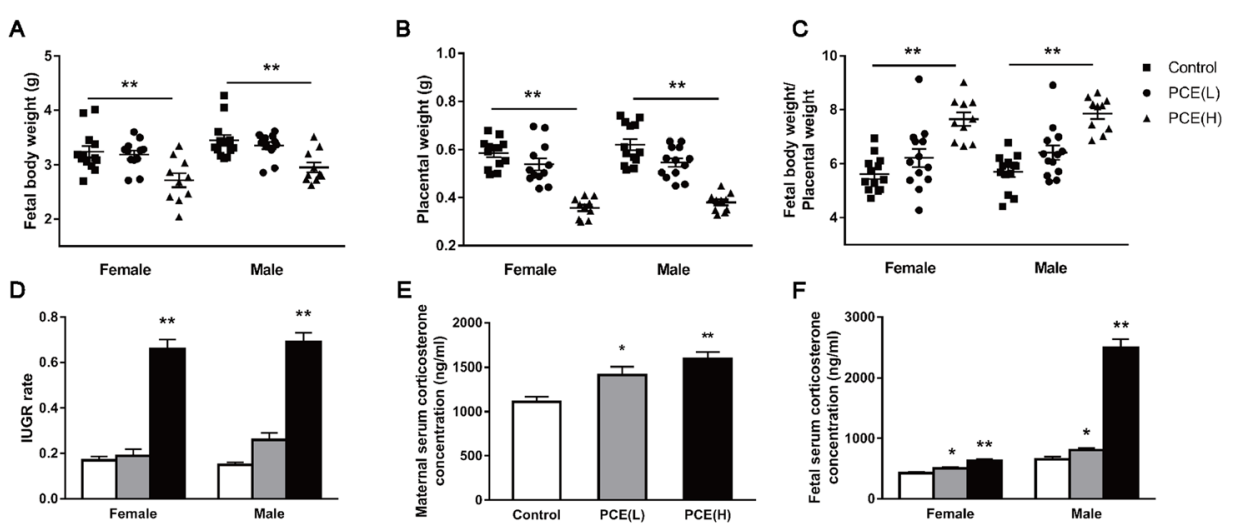

G

I
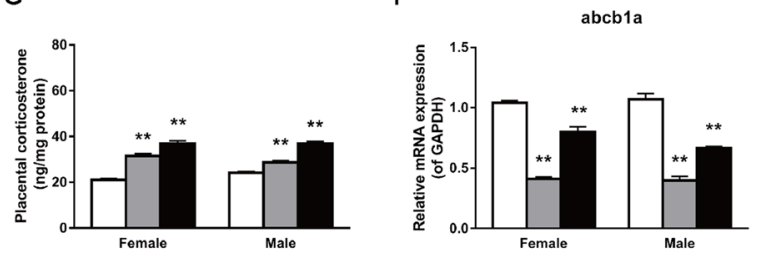

J

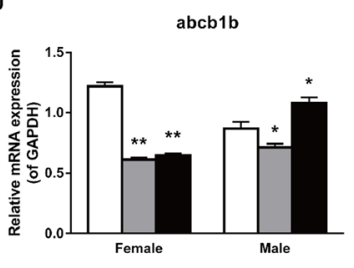

K
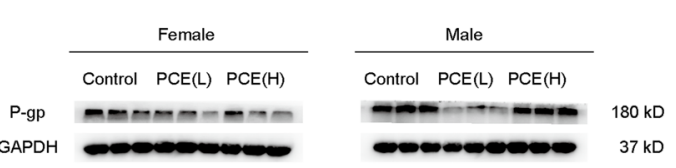

H Control $\quad$ PCE(L) $\quad$ PCE(H)
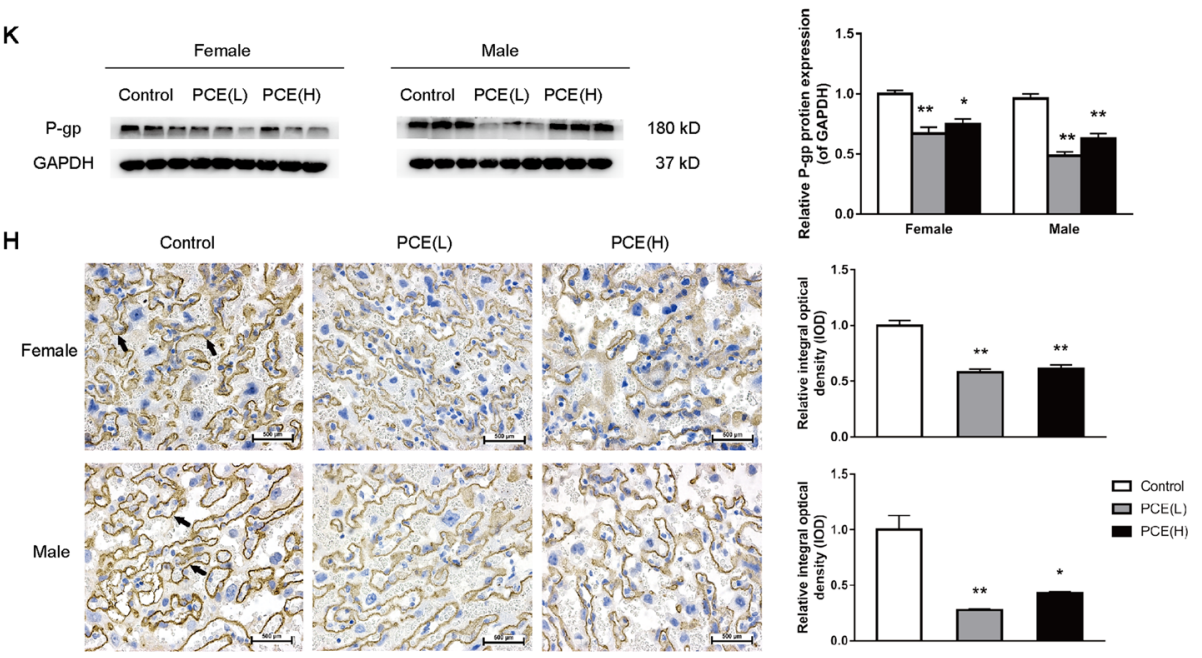

L

M

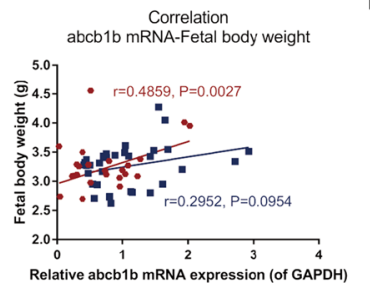

N

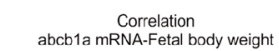

o
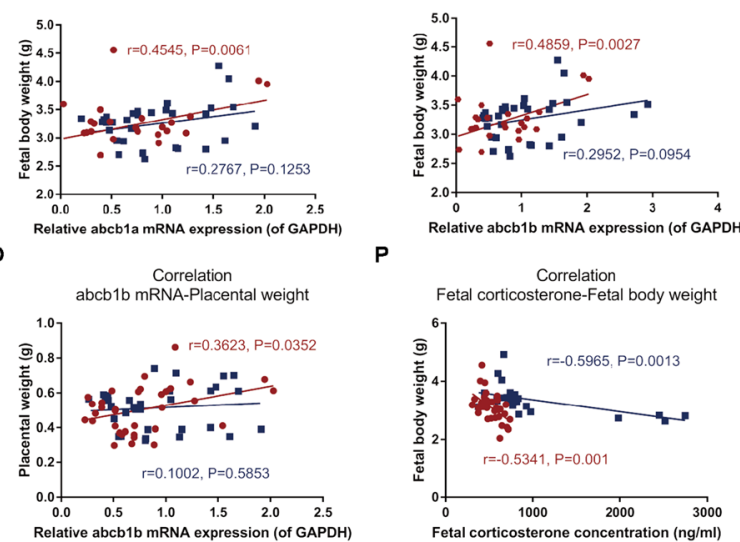

Q

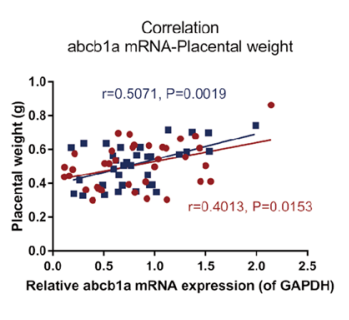

Correlation
Placental corticosterone-Placental weight

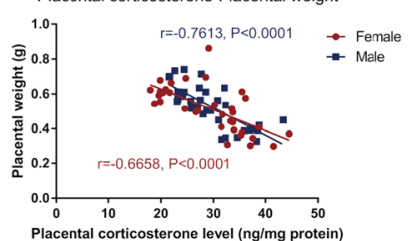

Fig. 2 (See legend on next page.) 
(See figure on previous page.)

Fig. 2 Changes of fetal body/placental weights, fetal serum/placental corticosterone levels, and placental P-glycoprotein (P-gp) expression in prenatal caffeine exposure (PCE)-related intrauterine growth retardation (IUGR) rat model. A Fetal body weight; B placental weight; C fetal body weight/placental weight; D IUGR rate; E-G corticosterone levels in maternal serum, fetal serum, and placentas; $\mathbf{H}$ immunostaining of P-gp (400X), $n=5 ; \mathbf{I}, \mathbf{J}$ relative mRNA expression levels of ATP-binding cassette, sub-family $\mathbf{B}$, member $1 \mathrm{a}$ (abcb1a) and abcb1b, $n=10-12$; $\mathbf{K}$ protein level of placental P-gp, $n=3$; L, $\mathbf{M}$ correlations between abcb1a or abcb1b mRNA expression levels and fetal body weights; $\mathbf{N}$, $\mathbf{O}$ correlations between abcb1a or abcb1b mRNA expression levels and placental weights; $\mathbf{P}$ correlations between fetal body weights and fetal serum corticosterone concentrations; $\mathbf{Q}$ correlation between placental weights and placental corticosterone levels. $n=34$. Mean \pm S.E.M. ${ }^{*} P<0.05$, ${ }^{* *} P<0.01$ vs. control

placental weights and IUGR rate were increased $(P<0.01$, Fig. 2A-D); the corticosterone levels in maternal serum, fetal serum, and placenta were significantly increased $(P<$ $0.05, P<0.01$, Fig. 2E-G). P-gp is encoded by a single gene (ABCB1) in humans, while there are two genes (abcbla and abcb1b) that are required to encode this protein in rodents [37]. Compared with the control group, the mRNA and protein levels of P-gp were significantly downregulated in the PCE group according to the qRT-PCR, Western blotting, and immunohistochemical analysis, and there was no significant difference in males and females $(P<0.05, P<0.01$, Fig. $2 \mathrm{H}-\mathrm{K})$. These results indicated the reduced fetal body weights, increased corticosterone levels in the placenta and fetal serum, and the inhibited placental P-gp expression in the PCE-induced IUGR rat model.

Next, we found that both abcb1a and abcb1b mRNA expression levels were positively correlated with fetal body weights in females $(P<0.05, P<0.01$, Fig. $2 \mathrm{~L})$ but not in males (Fig. 2M). We also found a positive correlation between abcb1a expression levels and placental weights in females and males $(P<0.05, P<0.01$, Fig. $2 \mathrm{~N})$. Additionally, abcb1b expression levels were positively correlated with placental weights in females $(P<0.05)$ but not in males (Fig. 2O). Meanwhile, we observed that fetal serum corticosterone levels were negatively correlated with fetal body weights and the placental corticosterone levels were negatively correlated with placental weights $(P<0.05, P<0.01$, Fig. $2 P, Q)$. These results indicate that the inhibition of fetal body/placental weights was not only associated with the reduction of P-gp expression but also the upregulation of fetal serum/placental glucocorticoid levels.

\section{Changes of placental RYR/JNK/YB-1 pathway and histone acetylation of the $a b c b 1 a / b$ promoter in PCE-induced IUGR rat model}

To verify the molecular mechanism of the inhibitory effect of PCE on P-gp expression, we detected the expression levels of 3 subtypes of RYR and the phosphorylation of JNK. The results showed that RYR1 and RYR3 mRNA expression levels were increased in the PCE group, as compared with the control group $(P<$ $0.05, P<0.01$, Fig. $3 \mathrm{~A}$ ), while RYR2 was not detected in the rat placenta. Besides, there was no significant change in total protein expression but increased phosphorylation of JNK in the PCE group $(P<0.05, P<$ 0.01 , Fig. 3B). Then, we further carried out the relevant experiments and found that the protein level of YB-1 in the nucleus of the PCE group was decreased $(P<0.05$, Fig. 3B). These findings indicated that the placental RYR1/3 expression levels were increased, the JNK signal was activated and the YB-1 nuclear translocation was inhibited in the PCE-induced IUGR rat model, and there was no significant difference in males and females.

To determine whether the epigenetic modifications of ABCB1 are involved in the inhibitory effect of PCE on Pgp expression, we further performed ChIP experiments. The results showed that H3K9ac and H3K14ac levels of placental ABCB1 were significantly reduced in PCErelated IUGR rats, as compared with the control group $(P<0.05, P<0.01$, Fig. $3 C$, D). P300 is a kind of acetyltransferase that plays an essential role in regulating the acetylation modifications in the gene promoter. Compared with the control group, the protein level of placental P300 was significantly decreased in the PCE-related IUGR group $(P<0.05$, Fig. $3 \mathrm{~B})$. These results indicated that the placental p300 expression and the histone acetylation levels of the abcbla and abcb1b promoter were reduced in the PCEinduced IUGR rat model, and there was no significant difference between the two sexes.

\section{Changes of P-gp expression, cortisol efflux, and related pathway in caffeine-treated placental trophoblasts}

To confirm the inhibitory effect of caffeine on P-gp expression in placental trophoblast cells, the primary trophoblasts extracted from the human placenta and the human trophoblast cell line BeWo cells were used for in vitro experiments. After treatment with different concentrations of caffeine $(0.1,1,10,100 \mu \mathrm{M})$ for $48 \mathrm{~h}$, it was found that the mRNA and protein expression levels of P-gp were significantly reduced in the above two types of cells $(P<0.05, P<0.01$, Fig. 4A-D). Rho 123 belongs to the substrate of $\mathrm{P}$-gp, and its fluorescence accumulation can reflect the transport activity of P-gp [38]. We found an increased rho 123 accumulation by caffeine in a concentration-dependent manner in BeWo cells $(P<0.01$, Fig. 4E), indicating that caffeine reduced P-gp activity. To prove the effect on the cortisol efflux transport capacity of trophoblasts by caffeine, we used an in vitro model of the placental barrier constructed by BeWo cells 


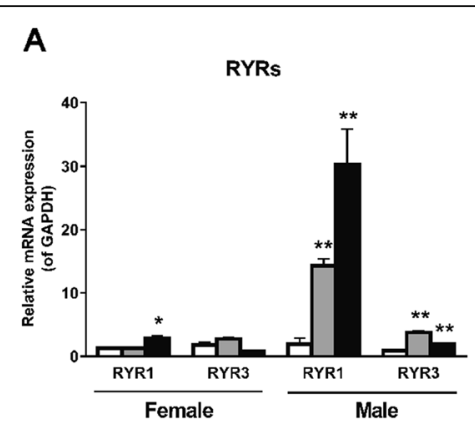

B
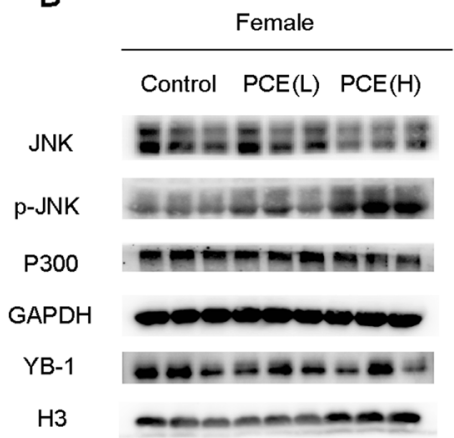

C
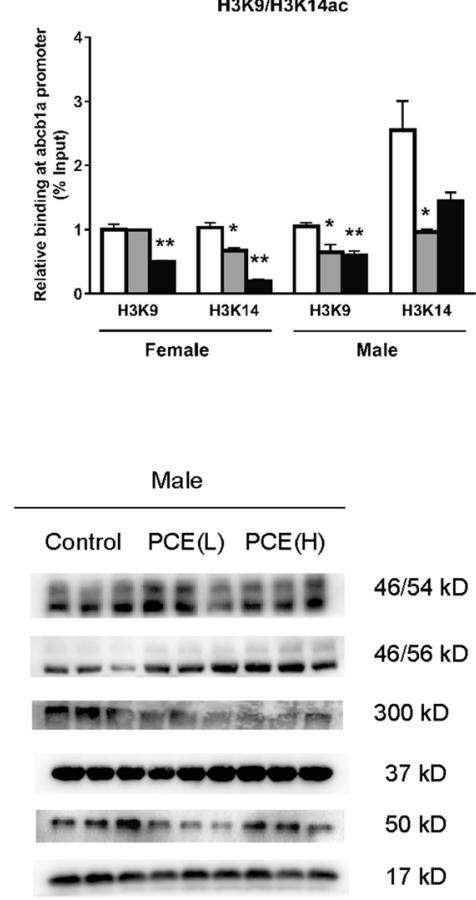

D
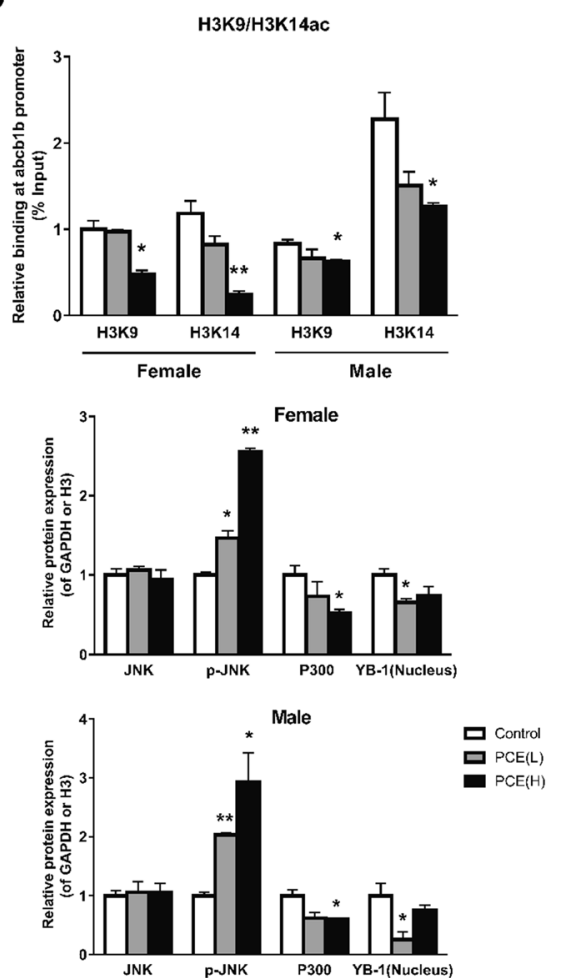

Fig. 3 Changes of placental ryanodine receptor/C-Jun N-terminal kinase/Y-box protein 1 (RYR/JNKYYB-1) pathway and histone acetylation of ATPbinding cassette, sub-family B, member $1 \mathrm{a} / \mathrm{b}(\mathrm{abcb} 1 \mathrm{a} / \mathrm{b})$ promoter region of prenatal caffeine exposure-induced intrauterine growth retardation rat model. A Relative mRNA expression levels of RYRs, $n=10-12$; B Relative protein expression of placental JNK, $p$-JNK, and E1A binding protein P300 (P300) was standardized by GAPDH, and relative protein expression of nucleus YB-1 was standardized by H3, $n=3$; C, D Histone 3 Lysine 9 (H3K9) and histone 3 Lysine 14 (H3K14) acetylation levels in the promoter region of abcb1a and abcb1b, $n=3$. Mean \pm S.E.M. ${ }^{*} P<0.05,{ }^{* *} P<0.01$ vs. control

using the Transwell chamber [39]. After the adding of cortisol in the upper chamber, the cortisol concentration was increased in the lower chamber after caffeine treatment $(P<0.01$, Fig. $4 \mathrm{~F})$, indicating the inhibited cortisol efflux capacity of P-gp by caffeine.

To further elucidate the molecular mechanism of P-gp expression inhibition, we tested the relevant indicators in the BeWo cells after caffeine treatment. Compared with the control group, the mRNA expression levels of RYR1 and RYR2 were increased in the caffeine group $(P<0.05$, Fig. 4G), while RYR3 expression level did not change significantly. And no apparent change in the protein expression of JNK but noted increased p-JNK protein level after caffeine treatment $(P<0.01$, Fig. $4 \mathrm{H})$. CoIP results showed that $\mathrm{p}$-JNK can interact with YB-1 (Fig. 4I). We found that compared with the control group, the protein level of nuclear YB-1 was decreased $(P<0.05, P<0.01$, Fig. $4 \mathrm{~J})$ and the binding level of $\mathrm{YB}-1$ on the $A B C B 1$ promoter was decreased in the caffeine group $(P<0.01$, Fig. $4 \mathrm{~K})$. These findings indicated that caffeine can induce the RYR $1 / 2$ and $p$-JNK expression, increase the interaction between $\mathrm{p}-\mathrm{JNK}$ and YB-1, and reduce the YB-1 nuclear translocation, thereby inhibiting the binding of $\mathrm{YB}-1$ on the $\mathrm{ABCB} 1$ promoter.

Furthermore, the protein level of P300 was decreased $(P<$ 0.01 , Fig. $4 \mathrm{H}$ ). We also observed an interaction between YB-1 and P300 in the nucleus of BeWo cells both in the control and caffeine-treated group by Co-IP experiments (Fig. 4I). Using Re-ChIP experiments, we further found that YB-1 and P300 bound to the same region of $\mathrm{ABCB} 1$ promoter, and the binding level of YB-1-P300 complex was downregulated after caffeine treatment $(P<0.01$, Fig. $4 \mathrm{~K})$. Besides, the H3K9 and H3K14 acetylation levels on the $\mathrm{ABCB} 1$ promoter were reduced in BeWo cells treating with caffeine $(P<0.01$, Fig. $4 \mathrm{~L})$. These results indicated the reduced recruitment of P300 by YB-1 by caffeine, which could further reduce the H3K9ac and H3K14ac levels on the $\mathrm{ABCB} 1$ promoter and inhibit $\mathrm{P}$-gp expression.

\section{Effects of RYRs, JNK inhibition, and YB-1 overexpression on P-gp expression and cortisol efflux function in BeWo cells}

To further verify that RYRs, JNK, and YB-1 are involved in the P-gp regulation, we observed the effects on P-gp 


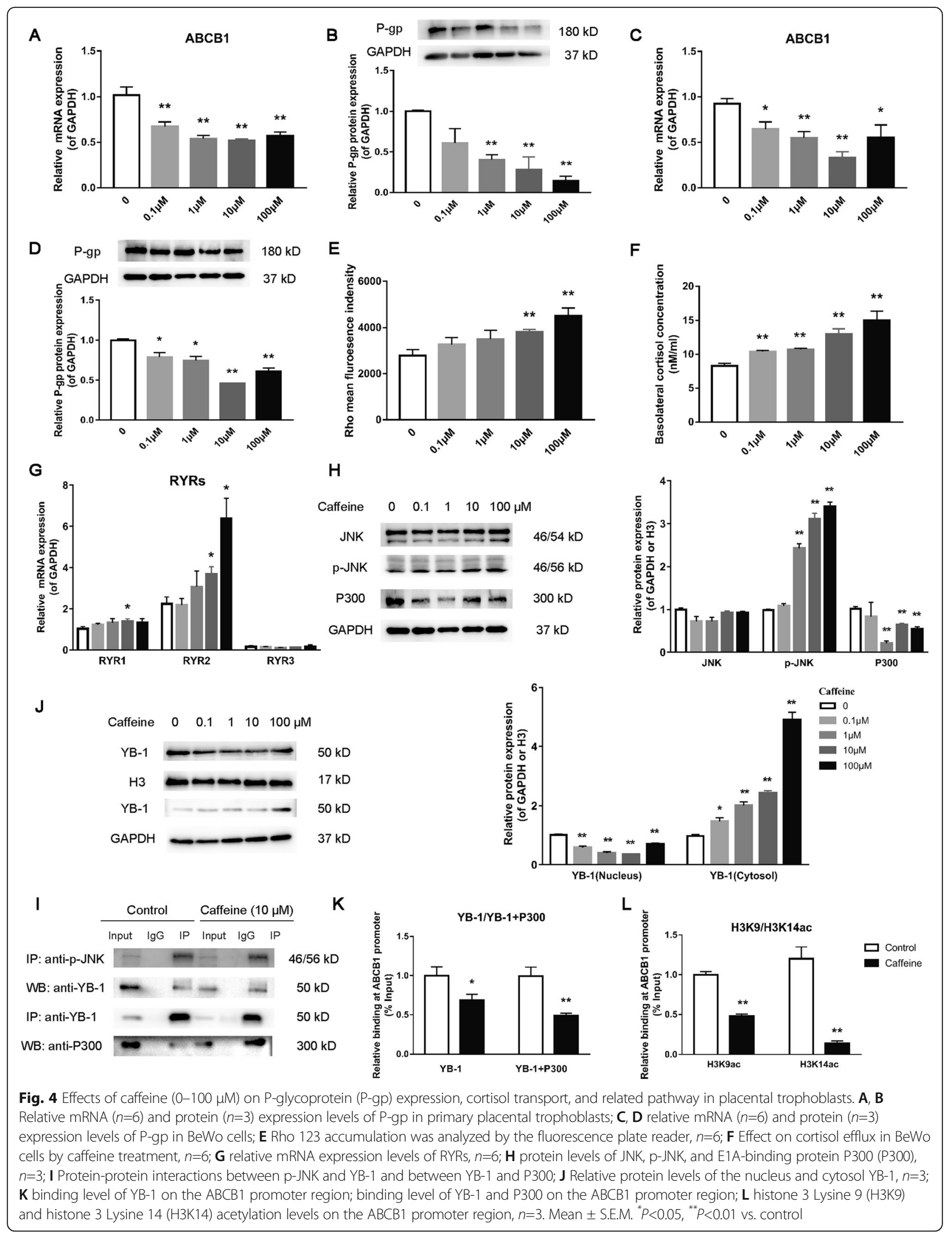


expression and related pathways by caffeine $(10 \mu \mathrm{M})$ alone or combined with dantrolene sodium (RYR antagonist, $10 \mu \mathrm{M}$ ), SP600125 (JNK inhibitor, $10 \mu \mathrm{M}$ ), and YB-1 plasmid transfection. As shown in Fig. 5, dantrolene sodium significantly reversed the caffeine-induced JNK phosphorylation, P-gp expression inhibition, and cortisol efflux $(P<0.05, P<0.01$, Fig. 5A-C). SP600125 significantly inhibited the JNK phosphorylation and reversed the inhibitory effect of caffeine on the protein level of nuclear YB-1 and P-gp and the efflux of cortisol $(P<0.05, P<0.01$, Fig. 5D-G). Next, the mRNA and protein expression levels of YB-1 were increased after the transfection of the YB-1 overexpression plasmid $(P<0.01$, Fig. 5H, I). The overexpression of YB-1 increased the $\mathrm{H} 3 \mathrm{~K} 9 \mathrm{ac}$ and H3K14ac levels on the ABCB1 promoter
$(P<0.05$, Fig. 5J). The P-gp expression inhibition and the cortisol efflux by caffeine can be reversed by the overexpression of YB-1 $(P<0.05, P<0.01$, Fig. $5 \mathrm{~K}, \mathrm{~L})$. These results indicated that the RYR/JNK/YB-1 pathway is involved in the P-gp expression suppression and cortisol efflux function by caffeine through epigenetic regulation.

\section{Effect of P-gp inducer sodium ferulate on fetal weight loss caused by PCE}

To confirm the regulation of P-gp on fetal weight loss, we observed the potential therapeutic effects of P-gp inducer sodium ferulate on fetal and placental weights induced by PCE. Both caffeine $(120 \mathrm{mg} / \mathrm{kg} \cdot \mathrm{d})$ and sodium ferulate $(50 \mathrm{mg} / \mathrm{kg} \cdot \mathrm{d})$ were administered from GD9 to GD18 by gavage. As shown in Table 3, compared with

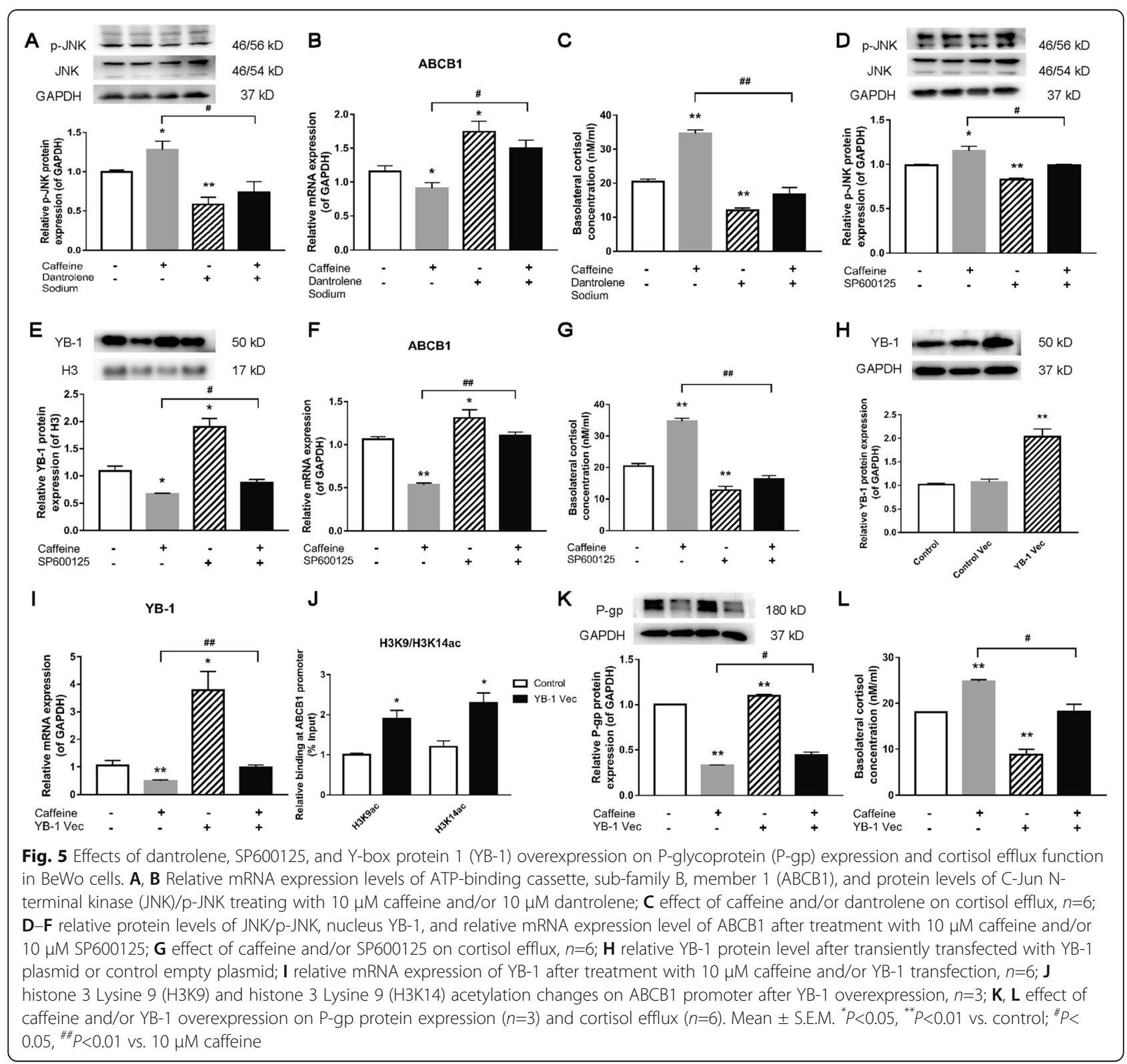


Table 3 Effect of P-gp inducer sodium ferulate on maternal weight gain rate, fetal body, and placental weights

\begin{tabular}{|c|c|c|c|c|c|}
\hline \multirow[t]{2}{*}{ Group } & \multirow{2}{*}{$\begin{array}{l}\text { Maternal } \\
\text { weight } \\
\text { gain rate } \\
\text { (\%) }\end{array}$} & \multicolumn{2}{|c|}{ Fetal body weight (g) } & \multicolumn{2}{|c|}{ Placental weight (g) } \\
\hline & & Female & Male & Female & Male \\
\hline Control & $52.0 \pm 1.5$ & $1.100 \pm 0.024$ & $1.100 \pm 0.026$ & $0.085 \pm 0.0037$ & $0.086 \pm 0.0031$ \\
\hline Caffeine & $40.0 \pm 1.7^{* *}$ & $0.850 \pm 0.026^{*}$ & $0.870 \pm 0.030$ * & $0.072 \pm 0.003^{* *}$ & $0.074 \pm 0.0025^{* *}$ \\
\hline Sodium ferulate & $52.0 \pm 1.5$ & $1.100 \pm 0.063$ & $1.200 \pm 0.062$ & $0.090 \pm 0.0031$ & $0.095 \pm 0.0039$ \\
\hline Caffeine + sodium ferulate & $47.0 \pm 2.8^{\#}$ & $0.990 \pm 0.062$ \#\# & $1.000 \pm 0.053 \#$ & $0.088 \pm 0.0029 \#$ & $0.093 \pm 0.0028 \#$ \\
\hline
\end{tabular}

the control, maternal weight gain rate, the male and female fetal and placental weights were significantly reduced in the caffeine groups $(P<0.05, P<0.01)$, but not significantly changed in the sodium ferulate groups. However, sodium ferulate could reverse the inhibitory effects of caffeine on the maternal body weight gain rate $(P<0.05)$ as well as the male and female fetal body and placental weights $(P<0.05, P<0.01)$. These results suggest that sodium ferulate can reverse the inhibitory effects of caffeine on the fetal body and placental weights.

Further, as shown in Fig. 6A-D, the protein expression levels of P-gp, as well as the mRNA of abcb1a/b, were reduced in the caffeine groups $(P<0.05, P<0.01)$ but increased in the sodium ferulate groups in both the male and female placentas, as compared with the control groups. Moreover, sodium ferulate could reverse the inhibitory effects of caffeine on P-gp expression in both male and female placentas $(P<0.05, P<0.01$, Fig. 6A-D). As for the placental and fetal serum corticosterone levels, they were increased in the caffeine groups $(P<$ $0.05, P<0.01)$ but were not significantly changed in the sodium ferulate groups, as compared with the control groups (Fig. 6E, F). Sodium ferulate could also reverse the enhancing effects of caffeine on the male and female placental and fetal serum corticosterone levels $(P<0.05$, $P<0.01$, Fig. $6 \mathrm{E}, \mathrm{F})$. These results suggest that sodium ferulate can reverse the inhibitory effects of caffeine on the placental P-gp expression and upregulation of the fetal serum/placental glucocorticoid levels.

\section{Correlations between JNK/YB-1/P300 pathway and P-gp expression in the human placentas}

Finally, we examined the changes of the JNK/YB-1/P300 pathway in the human placentas to confirm their involvement in placental P-gp regulation of IUGR neonates. Compared with the control, the protein level of placental p-JNK in the male neonates was significantly increased, while the mRNA expression level of YB-1 in both female and male neonates, as well as P300 in the male neonates, were significantly decreased in the IUGR group $(P<0.05, P<0.01$, Fig. $7 \mathrm{~A}-\mathrm{C})$. Furthermore, we observed that the placental $\mathrm{p}$-JNK protein levels in the male neonates were negatively correlated with $\mathrm{P}$-gp protein levels, while the mRNA expression levels of placental YB-1 in both female and male and P300 in female neonates were positively correlated with $\mathrm{P}$-gp protein levels $(P<0.05, P<0.01$, Fig. 7D-F). Moreover, the placental YB-1 expression levels were negatively correlated with fetal cord blood cortisol concentrations, while positively correlated with neonatal birth weights in female and male neonates $(P<0.05, P<0.01$, Fig. $7 \mathrm{G}-\mathrm{I})$. These results suggest that the placental JNK/YB-1/P300 pathway may participate in the occurrence of IUGR mediated by P-gp expression inhibition.

\section{Discussion}

The occurrence of IUGR was associated with P-gpmediated placental glucocorticoid barrier opening

A large number of previous studies in our lab have demonstrated that adverse environment during pregnancy (such as xenobiotics exposure and food intake restriction) can increase maternal and fetal glucocorticoid levels and partially compensate the fetal function development (thrifty phenotypic programming) to help the fetus get through the dangerous intrauterine period [40, 41]. However, such excessive maternal glucocorticoid exposure of the fetus can cause a higher risk of IUGR occurrence and an enhanced offspring's susceptibility to multiple adult diseases [41-43]. Clinical studies have shown that the fetal cord blood corticosteroid levels were negatively correlated with fetal body weights [15]. It is known that the placental glucocorticoid barrier plays an important role in protecting the fetus from excessive exposure to maternal glucocorticoids. As one of the "placental glucocorticoid barriers," P-gp is mainly expressed in the apical membrane of syncytiotrophoblasts, which can be in contact with maternal blood directly $[44,45]$. Studies have shown that the P-gp can efflux exogenous and endogenous substrates and mediate signal transduction and is involved in maintaining the normal structure and function of the placenta [4648]. However, the relationship between placental P-gp and IUGR is still unclear. In this study, P-gp expression in the human placenta was significantly reduced, and the placental and fetal cord blood cortisol levels were increased in the IUGR group. Besides, the neonatal birth 


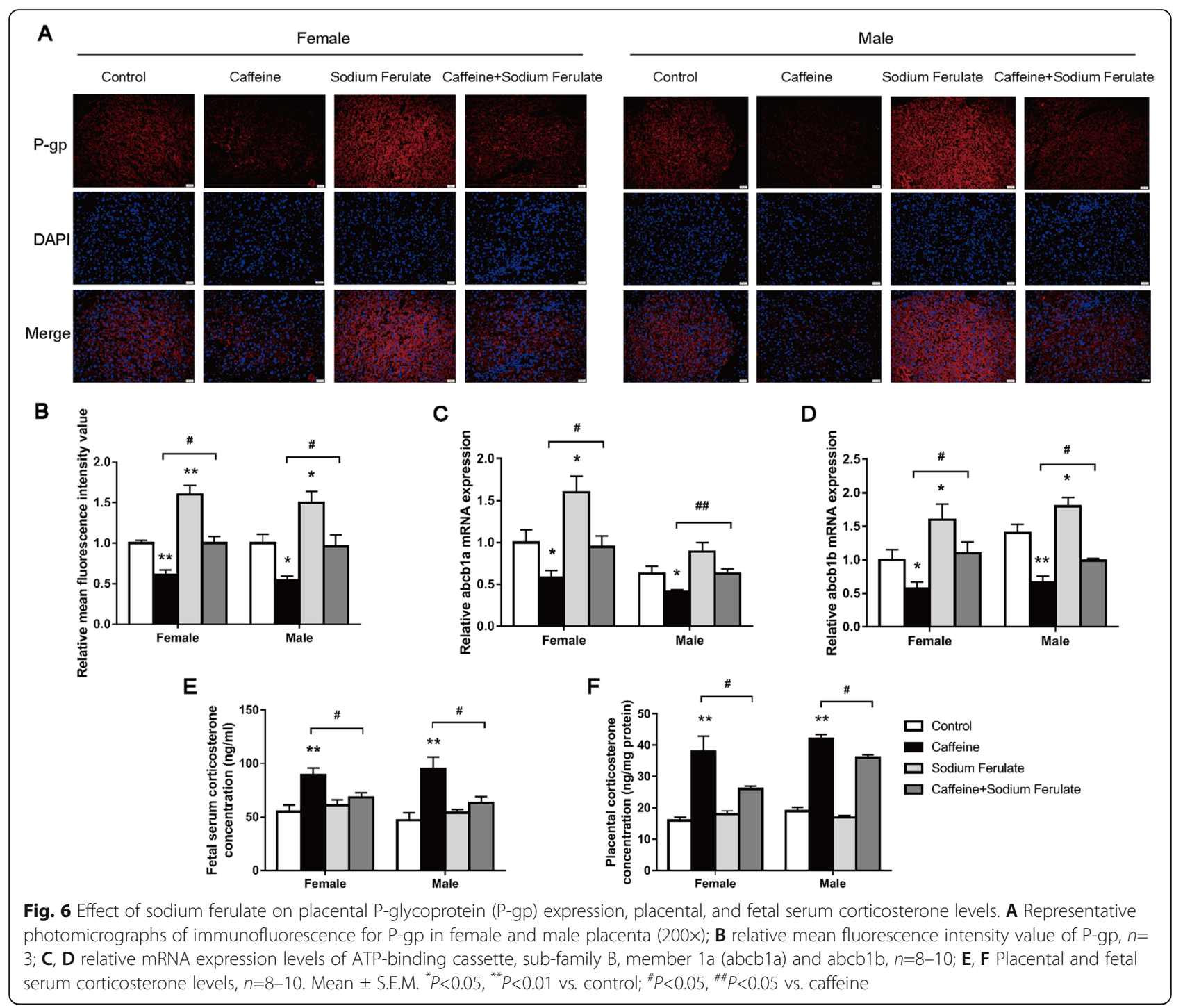

weight was positively correlated with the placental P-gp protein levels and negatively correlated with fetal cord blood cortisol levels. The results of the above human studies suggest that fetal weight loss is likely to be related to placental P-gp expression suppression and fetal overexposure to maternal glucocorticoids.

Epidemiological surveys pointed out that a lot of pregnant women consume caffeine worldwide, and the caffeine intake of some pregnant even exceeded $300 \mathrm{mg} / \mathrm{d}$ [49-51]. Evidence from WHO epidemiological studies demonstrated that caffeine consumption exceeding 300 $\mathrm{mg} / \mathrm{d}$ will increase the risk of IUGR occurrence, and the developmental toxicity increased with caffeine intak $\mathrm{e}[52,53]$. Previous studies in our laboratory have found that daily dose of caffeine exposure $[20 \mathrm{mg} / \mathrm{kg} \cdot \mathrm{d}$ in rats, equivalent to $194 \mathrm{mg}$ of caffeine per day for a $60 \mathrm{~kg}$ woman according to the dose conversion between humans and rats (1:6.17)] can cause an increased rate of
IUGR occurrence, dysplasia of multiple organs (including the hippocampus, adrenal gland, liver, bone), and susceptibility to multiple chronic diseases, such as nonalcoholic fatty liver, metabolic syndrome, and osteoarthritis, which are related to PCE-induced maternal glucocorticoid overexposure [16, 23-26]. In this study, by using the PCE-induced IUGR rat model, we analyzed the role of placental P-gp in mediating the IUGR occurrence and clarified its underlying mechanism. The results showed that the fetal body weight was significantly decreased and the IUGR rate was increased (female: 66\% vs. $17 \%$; male: $69 \%$ vs. $15 \%)$ in the $\mathrm{PCE}(\mathrm{H})$ group, indicating that the IUGR rat model was successfully established. Further, we found that PCE significantly reduced the mRNA and protein expression levels of placental Pgp and increased the corticosterone levels in the placental tissue and fetal serum. The correlation analysis indicated that the mRNA expression levels of placental 


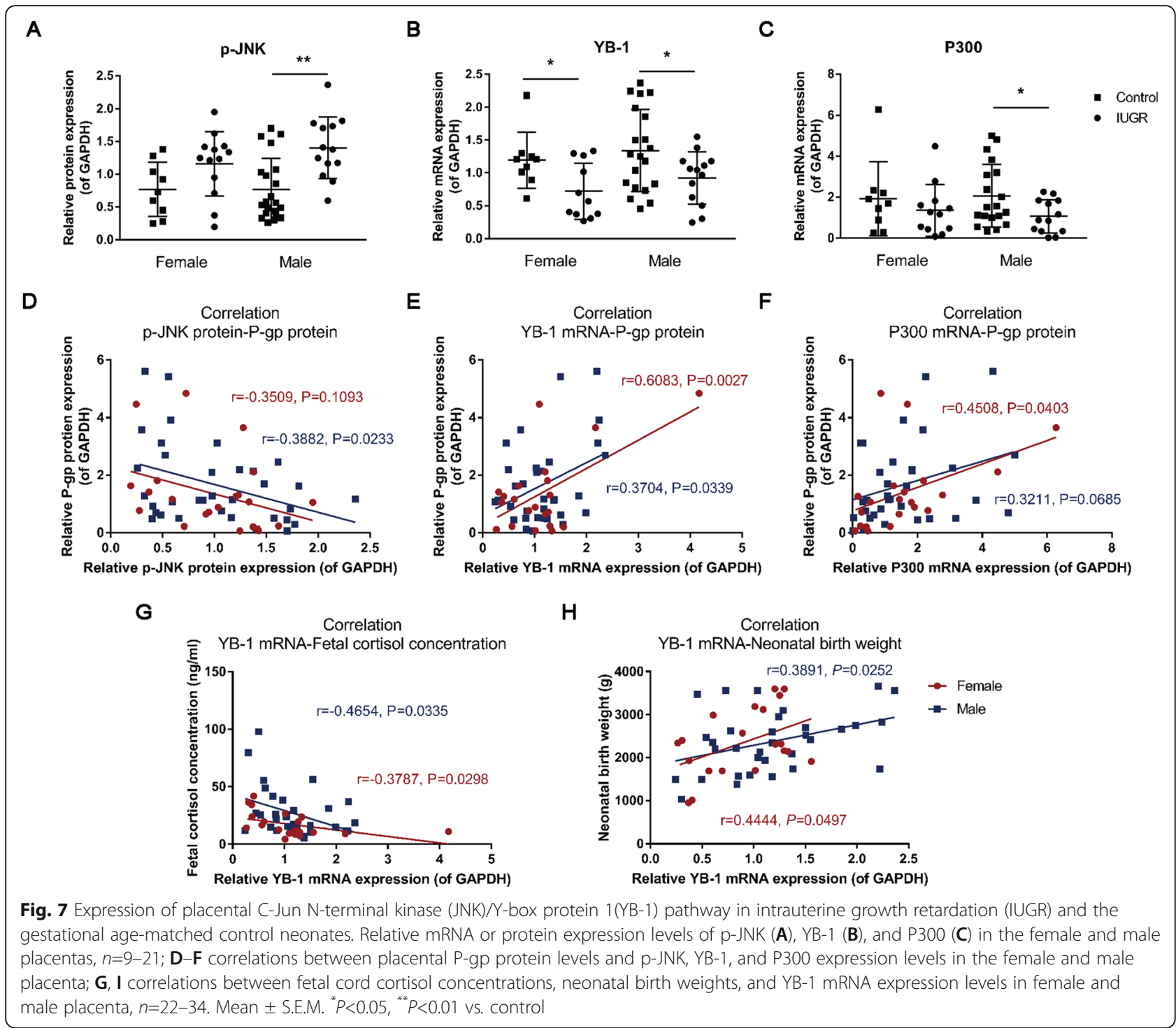

abcb1a/b were positively correlated with placental/fetal weights, while the corticosterone levels in the placenta and fetal serum were negatively correlated with placental and fetal weights, respectively. These results were consistent with changes in multiple indicators of the clinical IUGR specimens.

BeWo cell is an in vitro model commonly used for studying placental function. Using the transport model constructed by BeWo cells, studies have found that overexpression of $\mathrm{P}$-gp can restrict the passage of cortisol and dexamethasone [54, 55]. In this study, using the same transport model, we confirmed that caffeine can inhibit the P-gp expression and cortisol efflux of trophoblasts. All the above results indicate that PCE (caffeine) on the one hand increases maternal glucocorticoid level, and on the other hand, it opens the placental glucocorticoid barrier by inhibiting placental P-gp expression, thereby increasing the fetal glucocorticoid concentration and inhibiting fetal development. Previous studies have confirmed the impaired structure and function of the rat placenta in the PCE model [56]. It has also been reported that excessive glucocorticoids can impair placental development and function [12, 17]. The present study confirmed that PCE increased the glucocorticoid level in the placenta, and the excessive placental glucocorticoids can inhibit placental development and further affected fetal development. Noteworthy, although PCE reduced both the fetal body and placental weight, the ratio of fetal body/placental weight was increased. According to the characteristic change of "smaller placenta and bigger fetus," we speculate that the fetal growth and development under PCE have been compensated to a certain 
extent, which is related to fetal multi-organ "thrifty phenotype" development caused by intrauterine glucocorticoid overexposure [42, 57].

\section{RYR/JNK/YB-1 pathway mediates the inhibition of P-gp expression in the placenta of IUGR rats induced by caffeine}

Studies have shown that there are 3 subtypes of RYRs, and caffeine can increase the sensitivity of RYRs [58]. However, whether RYRs are involved in the regulation of placental P-gp by caffeine has not been reported. In the present study, we found that the rat placenta mainly expressed RYR1 and RYR3, while human trophoblasts mainly expressed RYR1 and RYR2. Caffeine increased the expression levels of RYR1 and RYR2 in the trophoblasts, while RYR antagonist can reverse the inhibitory effect of caffeine on P-gp expression and cortisol efflux. The studies have shown that the increased sensitivity of RYRs can reduce the threshold of spontaneous $\mathrm{Ca}^{2+}$ release from the endoplasmic reticulum [59]; the ozone in the spinal cord neurons can activate JNK/MAPK signaling by inducing the release of endoplasmic reticulum $\mathrm{Ca}^{2+}$, leading to neurotoxicity [60]. In this study, caffeine activated the JNK pathway, while inhibiting JNK can reverse the effect of caffeine on P-gp expression and cortisol efflux, indicating that the JNK pathway is involved in caffeine-induced inhibition of P-gp expression and opening of glucocorticoid barrier. YB-1 is an important member of the Y-box protein family, which can regulate gene transcription, translation, stress, and DNA repair [28]. Studies have shown that the overexpression of JNK1 or the activation of JNK signaling can inhibit YB-1 from entering the nucleus in MCF-7/Dox cells [27]. It is found that $\mathrm{p}-\mathrm{JNK}$ can interact with YB-1 in BeWo cells in our study, while the inhibition of JNK can reverse the effect of caffeine on YB-1 nuclear translocation, indicating that $\mathrm{p}-\mathrm{JNK}$ can bind to YB-1 and inhibit YB-1 from entering the nucleus after caffeine activates JNK signaling. We further found that caffeine can inhibit the binding of $\mathrm{YB}-1$ to the $\mathrm{ABCB} 1$ promoter region. The inhibitory effect of caffeine on P-gp expression and cortisol efflux was canceled after YB-1 overexpression, suggesting that the reduction of YB-1 nuclear translocation mediates the transcriptional inhibition of P-gp and the opening of the placental glucocorticoid barrier induced by caffeine.

Recently, research on the epigenetic regulation of P-gp has been limited to studies about tumor [61]. However, its histone acetylation mechanism in the placenta has not been reported yet. A previous study demonstrated that drug-induced acetylation of apurinic/apyrimidinic endonuclease 1 can enhance the formation of the YB-1/ p300 complex on the gene promoter in HEK-293T cells [62]. As an acetyltransferase, P300 plays an important role in regulating the epigenetic modification of genes. In this study, YB-1 can interact with P300, and the two can bind to the same $\mathrm{ABCB} 1$ promoter region, while caffeine can inhibit the binding of the YB-1-P300 complex to the $\mathrm{ABCB} 1$ promoter. Our study also shown that P300 expression, and ABCB1 (or abcb1a/b) promoter H3K9ac and H3K14ac levels were significantly reduced in the placenta in PCE-induced IUGR rats, as well as in BeWo cells treated with caffeine, and further overexpression of $\mathrm{YB}-1$ can increase the ABCB1 promoter H3K9ac and H3K14ac levels. These results indicate that caffeineinduced decrease of YB-1 nuclear translocation can reduce the recruitment of $\mathrm{P} 300$ and inhibit the binding of the two proteins on the $\mathrm{ABCB} 1$ promoter, resulting in decreases of H3K9ac and H3K14ac levels of P-gp promoter and P-gp expression.

Taken together, PCE can inhibit the P-gp expression in placental trophoblast cells, and its underlying mechanism is related to the fact that caffeine can activate the RYR/JNK signaling, and promote the binding of $\mathrm{p}-\mathrm{JNK}$ to $\mathrm{YB}-1$, thereby inhibiting the expression of $\mathrm{YB}-1$ and its nuclear translocation. The reduction of YB-1 in the nucleus, on the one hand, directly inhibits P-gp transcription; on the other hand, it inhibits the recruitment of P300 and reduces histone acetylation (H3K9 and H3K14) of the P-gp promoter, thus enhancing the inhibitory effect on the placental P-gp expression (Additional file 1: Figure S1).

\section{Potential early warning, prevention, and treatment target for IUGR}

P-gp can prevent excessive exogenous and endogenous harmful substances from entering the fetal circulation, so the P-gp inducer may become the potential therapeutic target of IUGR. Previous studies in our and other laboratories have suggested that P-gp inducers sodium ferulate and tadalafil can effectively reverse the weight loss of fetal mice caused by prenatal tobacco/alcohol exposure or preeclampsia [63, 64]. Sodium ferulate has been widely used to prevent diseases related to reactive oxygen species, such as cancer, cardiovascular disease, and diabetes [65]. In this study, $50 \mathrm{mg} / \mathrm{kg} \cdot \mathrm{d}$ sodium ferulate did not significantly change the fetal body and placental weights, indicating that this dose has no apparent toxicity to the placenta and fetal development. However, sodium ferulate can reverse the effects of PCE on the fetal body/placental weight, placental P-gp expression, and the fetal serum/placental corticosterone levels, suggesting that P-gp is the prevention and treatment target of IUGR.

The detection of the related epigenetic markers (e.g., H3K9ac and H3K4ac) and the key signal molecules of Pgp in maternal can be used as potential early warning biomarkers of IUGR. In this study, using detecting the clinical 
specimens, we found that the p-JNK protein level was increased, and YB-1 and P300 were significantly decreased in the male placenta of the IUGR group, while only the YB-1 expression level in the female placenta of the IUGR group was significantly decreased. Furthermore, the placental p-JNK protein levels in the male newborns were negatively correlated with P-gp protein levels, while placental YB-1 expression levels in both females and males as well as P300 expression levels in the females, were positively correlated with P-gp protein levels. These results suggest that JNK/YB-1/P300 pathway may be the common regulatory pathway for P-gp expression inhibition in IUGR neonates under various adverse environments during pregnancy, among which the expression of YB-1 is the most stable and closely correlated with the fetal weight. To further determine the relationship among the P-gp, its important regulator YB-1, and the other IUGR models, we also tested other IUGR rat models induced by prenatal dexamethasone and ethanol exposure. The results demonstrated that the mRNA and protein expression levels of Pgp and YB-1 in the placentas were inhibited, and the placental abcb1a/b expression levels were positively correlated with the body weights in the female and male fetal rats (Additional file 1: Figure S2, S3). Based on these, we propose that YB-1 can be used as a potential early warning target of placental glucocorticoid barrier opening, the occurrence of IUGR, and susceptibility to multiple diseases.

More and more studies have reported that specific genes and their epigenetic modifications in the placenta can be used as biomarkers of abnormal placental and fetal development under adverse environments during pregnancy and can be released into the maternal blood in the form of exosomes [66-68]. It is known that genes expressed in human peripheral blood cells (PBMCs) could overlap with $80 \%$ of genes expressed in other tissues [69]. Peripheral blood mononuclear cells are defined as any blood cell with a round nucleus (i.e., lymphocytes, monocytes, or macrophages), which are biological samples that are easily obtained in clinical practice. The epigenetic modification and expression of some genes in PBMCs are consistent with that of tissues and can be used as a substitute biomarker for tissues and organs [70, 71]. Therefore, the use of maternal blood exosomes or PBMCs for early warning of placental biomarkers has great potential. In this study, based on the important role of P-gp and YB-1 in mediating the IUGR occurrence, we proposed that the detection of the expression of P-gp, YB-1, and related epigenetic markers in maternal blood exosomes or PBMC may become an early warning target of IUGR. Unfortunately, we have not collected enough blood samples from pregnant women for further detection and validation of placental epigenetic biomarkers.

\section{Conclusions}

In conclusion, for the first time, we demonstrate that the inhibition of P-gp expression mediates the opening of the placental glucocorticoid barrier and fetal weight loss in clinical IUGR specimens and PCE-induced IUGR rat

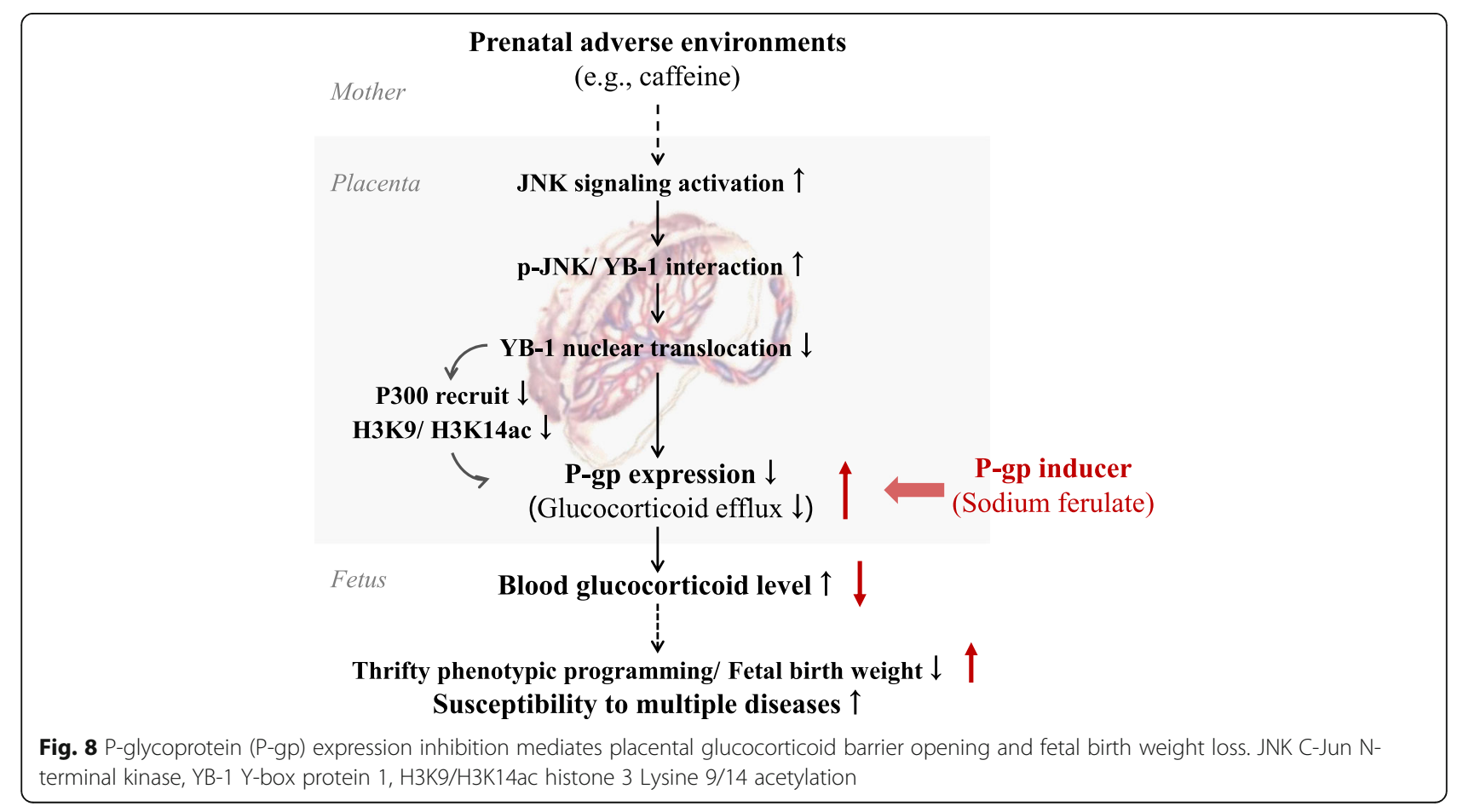


model. Further, we used the rat IUGR model and BeWo cells to confirm that the mechanism is related to the activated JNK signal, which in turn inhibits the YB-1 expression and nuclear translocation, thereby directly inhibiting P-gp transcription. YB-1 expression inhibition can also decrease P-gp promoter acetylation and expression by reducing the recruitment of P300 (Fig. 8). Sodium ferulate intervention study confirmed that P-gp inducer can reverse the effect of caffeine on the fetal/ placental weights, suggesting that P-gp is a target for the prevention and treatment of IUGR. Finally, the studies of clinical specimens and series IUGR animal models confirmed that the JNK/YB-1 pathway is the common regulation mechanism of $\mathrm{P}$-gp expression, and YB-1 is the potential early warning target of placental glucocorticoid barrier opening, the occurrence of IUGR, and susceptibility of multiple diseases.

\section{Abbreviations}

IUGR: Intrauterine growth retardation; MS: Metabolic syndrome; PCE: Prenatal caffeine exposure; ABCB1: ATP-binding cassette subfamily B member 1; Pgp: P-glycoprotein; RYR: Ryanodine receptor; JNK: C-Jun N-terminal kinase; YB-1: Y-box protein 1; H3K9ac: Histone 3 Lysine 9 acetylation

\section{Supplementary Information}

The online version contains supplementary material available at https://doi. org/10.1186/s12916-021-02173-4

Additional File 1: Figures S1-S3. Figure S1. Schematic representation of the postulated molecular pathway by which inhibits placental Pglycoprotein (P-gp) expression in prenatal caffeine exposure-induced intrauterine growth retardation rat model. Figure S2. Changes of fetal body/placental weights, placental P-glycoprotein (P-gp) and Y-box protein 1 (YB-1) expression levels in prenatal dexamethasone exposure (PDE)-related intrauterine growth retardation (IUGR) rat model. Figure S3. Changes of fetal body/placental weights, placental P-glycoprotein (Pgp) and Y-box protein 1 (YB-1) expression levels in prenatal ethanol exposure (PEE)-related intrauterine growth retardation (IUGR) rat model.

\section{Acknowledgements}

The authors would like to thank the staff of Wuhan University Center for the animal experiment.

\section{Authors' contributions}

CG, DX (the second author), YZ, and HW designed the study. CG, PY, and MF performed the experiments and collected the data. SC, YQ, and JG provided technical assistance for the experiments. CG, PY, MF, DX (the sixth author), and JG collected the clinical data and samples. CG and DX ${ }^{a}$ wrote the manuscript. YZ and HW supervised the study. The authors approved the final manuscript.

\section{Funding}

This work was supported by grants from the National Key R\&D Program of China (No. 2020YFA0803900), the National Natural Science Foundation of China (No. 82030111, 81973405, 81903329), the Major Technological Innovation Projects of Hubei Province (No. 2019ACA140, 2020BCA071), Hubei Province's Outstanding Medical Academic Leader program, the Medical Science Advancement Program (Basic Medical Sciences) of Wuhan University (No. TFJC2018001), and Translational Medicine and Interdisciplinary Research Joint Fund of Zhongnan Hospital of Wuhan University (Grant No. ZNLH201908).

\section{Availability of data and materials}

The datasets used and/or analyzed during the current study are available from the corresponding author on reasonable request.

\section{Declarations}

\section{Ethics approval and consent to participate}

The study was approved by the Medical Ethical Committee of Zhongnan Hospital of Wuhan University (approval number 201606). All participants provided written informed consent for collecting the placentas and fetal cord blood and further analysis.

\section{Consent for publication}

Not applicable.

\section{Competing interests}

The authors declare that they have no competing interests.

\section{Author details}

${ }^{1}$ Department of Obstetrics and Gynaecology, Zhongnan Hospital of Wuhan University, 169 Donghu Road, Wuchang District, Wuhan 430071, China. 2Department of Pharmacology, Basic Medical School of Wuhan University, 185 Donghu Road, Wuchang District, Wuhan 430071, China. ${ }^{3}$ Hubei Provincial Key Laboratory of Developmentally Originated Diseases, 185 Donghu Road, Wuchang District, Wuhan 430071, China.

Received: 20 June 2021 Accepted: 26 October 2021

Published online: 08 December 2021

\section{References}

1. Martín-Estal I, de la Garza RG, Castilla-Cortázar I. Intrauterine growth retardation (IUGR) as a novel condition of insulin-like growth factor-1 (IGF-1) deficiency. Rev Physiol Biochem Pharmacol. 2016;170:1-35. https://doi.org/1 0.1007/112_2015_5001.

2. Faraci M, Renda E, Monte S, Di Prima FA, Valenti O, De Domenico R, et al. Fetal growth restriction: current perspectives. J Prenat Med. 2011;5(2):31-3.

3. Shrivastava D, Master A. Fetal growth restriction. J Obstet Gynaecol India. 2020;70(2):103-10. https://doi.org/10.1007/s13224-019-01278-4.

4. Lee AC, Kozuki N, Cousens S, Stevens GA, Blencowe H, Silveira MF, et al. Estimates of burden and consequences of infants born small for gestational age in low and middle income countries with INTERGROWTH-21(st) standard: analysis of CHERG datasets. BMJ. 2017;358:3677.

5. Meas T, Deghmoun S, Alberti C, Carreira E, Armoogum P, Chevenne D, et al Independent effects of weight gain and fetal programming on metabolic complications in adults born small for gestational age. Diabetologia. 2010; 53(5):907-13. https://doi.org/10.1007/s00125-009-1650-y.

6. Darendeliler F. IUGR: genetic influences, metabolic problems, environmental associations/triggers, current and future management. Best Pract Res Cl En. 2019;33(3):101260. https://doi.org/10.1016/j.beem.2019.01.001.

7. Sacchi C, Marino C, Nosarti C, Vieno A, Visentin S, Simonelli A. Association of intrauterine growth restriction and small for gestational age status with childhood cognitive outcomes: a systematic review and meta-analysis. JAMA Pediatr. 2020;174(8):772-81. https://doi.org/10.1001/jamapediatrics.202 0.1097 .

8. Golden TN, Simmons RA. Immune dysfunction in developmental programming of type 2 diabetes mellitus. Nat Rev Endocrinol. 2021;17(4): 235-45. https://doi.org/10.1038/s41574-020-00464-z.

9. Baldauf C, Sondhi M, Shin BC, Ko YE, Ye X, Lee KW, et al. Murine maternal dietary restriction affects neural humanin expression and cellular profile. J Neurosci Res. 2020;98(5):902-20. https://doi.org/10.1002/jnr.24568.

10. Yu L, Zhou J, Zhang G, Huang W, Pei L, LV F, et al. CAMP/PKA/EGR1 signaling mediates the molecular mechanism of ethanol-induced inhibition of placental 11ß-HSD2 expression. Toxicol Appl Pharmacol. 2018;352:77-86. https://doi.org/10.1016/j.taap.2018.05.029.

11. Zinkhan EK, Yu B, Callaway CW, McKnight RA. Intrauterine growth restriction combined with a maternal high-fat diet increased adiposity and serum corticosterone levels in adult rat offspring. J Dev Orig Health Dis. 2018;9(3): 315-28. https://doi.org/10.1017/S2040174418000016.

12. Busada JT, Cidlowski JA. Mechanisms of glucocorticoid action during development. Curr Top Dev Biol. 2017;125:147-70. https://doi.org/10.1016/ bs.ctdb.2016.12.004. 
13. Konstantakou P, Mastorakos G, Vrachnis N, Tomlinson JW, Valsamakis G. Dysregulation of 11 beta-hydroxysteroid dehydrogenases; implications during pregnancy and beyond. J Matern-Fetal Neo M. 2017;30(3):284-93. https://doi.org/10.3109/14767058.2016.1171308.

14. Sheng JA, Bales NJ, Myers SA, Bautista Al, Roueinfar M, Hale TM, et al. The hypothalamic-pituitary-adrenal axis: development, programming actions of hormones, and maternal-fetal interactions. Front Behav Neurosci. 2020;14: 601939. https://doi.org/10.3389/fnbeh.2020.601939.

15. Moisiadis VG, Matthews SG. Glucocorticoids and fetal programming part 2: mechanisms. Nat Rev Endocrinol. 2014;10(7):403-11. https://doi.org/10.1038/ nrendo.2014.74

16. Xu D, Zhang B, Liang G, Ping J, Kou H, Li X, et al. Caffeine-induced activated glucocorticoid metabolism in the hippocampus causes hypothalamicpituitary-adrenal axis inhibition in fetal rats. PLoS One. 2012;7(9):e44497. https://doi.org/10.1371/journal.pone.0044497.

17. Zhou J, Liu F, Yu L, Xu D, Li B, Zhang G, et al. nAChRs-ERK1/2-Egr-1 signaling participates in the developmental toxicity of nicotine by epigenetically down-regulating placental 11ß-HSD2. Toxicol Appl Pharmacol. 2018;344:1-12. https://doi.org/10.1016/j.taap.2018.02.017.

18. Chatuphonprasert W, Jarukamjorn K, Ellinger I. Physiology and pathophysiology of steroid biosynthesis, transport and metabolism in the human placenta. Front Pharmacol. 2018;9:1027. https://doi.org/10.3389/fpha r.2018.01027.

19. Hoyt AT, Browne M, Richardson S, Romitti P, Druschel C. Maternal caffeine consumption and small for gestational age births: results from a population-based case-control study. Matern Child Health J. 2014;18(6): 1540-51. https://doi.org/10.1007/s10995-013-1397-4.

20. Galéra C, Bernard JY, van der Waerden J, Bouvard MP, Lioret S, Forhan A, et al. Prenatal caffeine exposure and child IQ at age 5.5 years: the EDEN mother-child cohort. Biol Psychiatry. 2016;80(9):720-6. https://doi.org/10.101 6/j.biopsych.2015.08.034.

21. Kobayashi S, Sata F, Murata K, Saijo Y, Araki A, Miyashita C, et al. Dosedependent associations between prenatal caffeine consumption and small for gestational age, preterm birth, and reduced birthweight in the Japan environment and children's study. Paediatr Perinat Epidemiol. 2019;33(3): 185-94. https://doi.org/10.1111/ppe.12551.

22. Leviton A. Biases inherent in studies of coffee consumption in early pregnancy and the risks of subsequent events. Nutrients. 2018;10(9):1152. https://doi.org/10.3390/nu10091152.

23. He Z, Lv F, Ding Y, Huang H, Liu L, Zhu C, et al. High-fat diet and chronic stress aggravate adrenal function abnormality induced by prenatal caffeine exposure in male offspring rats. Sci Rep. 2017;7(1):14825. https://doi.org/10.1 038/s41598-017-14881-0.

24. Lv F, Fan G, Wan $Y$, Chen $Y, N i$, Huang J, et al. Intrauterine endogenous high glucocorticoids program ovarian dysfunction in female offspring secondary to prenatal caffeine exposure. Sci Total Environ. 2021;789:147691. https://doi.org/10.1016/j.scitotenv.2021.147691.

25. Pei LG, Yuan C, Guo YT, Kou H, Xia LP, Zhang L, et al. Prenatal caffeine exposure induced high susceptibility to metabolic syndrome in adult female offspring rats and its underlying mechanisms. Reprod Toxicol. 2017; 71:150-8. https://doi.org/10.1016/j.reprotox.2017.06.045.

26. Tan Y, Lu K, Li J, Ni Q, Zhao Z, Magdalou J, et al. Prenatal caffeine exposure increases adult female offspring rat's susceptibility to osteoarthritis via lowfunctional programming of cartilage IGF-1 with histone acetylation. Toxicol Lett. 2018;295:229-36. https://doi.org/10.1016/j.toxlet.2018.06.1221.

27. Choi YK, Cho SG, Choi HS, Woo SM, Yun YJ, Shin YC, et al. JNK1/2 activation by an extract from the roots of Morus alba $L$. reduces the viability of multidrug-resistant MCF-7/Dox cells by inhibiting YB-1-dependent MDR1 expression. Evid Based Complement Alternat Med. 2013;2013(6):741985.

28. Sobočan M, Bračič S, Knez J, Takač I, Haybaeck J. The communication between the PI3K/AKT/mTOR pathway and Y-box binding protein-1 in gynecological cancer. Cancers. 2020;12(1):205.

29. Priante E, Verlato G, Giordano G, Stocchero M, Visentin S, Mardegan V, et al. Intrauterine growth restriction: new insight from the metabolomic approach. Metabolites. 2019;9(11):267.

30. Henley D, Brown S, Pennell C, Lye S, Torpy DJ. Evidence for central hypercortisolism and elevated blood pressure in adolescent offspring of mothers with pre-eclampsia. Clin Endocrinol (Oxf). 2016;85:583-9.

31. Eberle C, Fasig T, Brüseke F, Stichling S. Impact of maternal prenatal stress by glucocorticoids on metabolic and cardiovascular outcomes in their offspring: a systematic scoping review. PLoS One. 2021;16(1):e0245386. https://doi.org/10.1371/journal.pone.0245386.

32. Xu D, Xia LP, Shen L, Lei $Y Y$, Liu L, Zhang $L$, et al. Prenatal nicotine exposure enhances the susceptibility to metabolic syndrome in adult offspring rats fed high-fat diet via alteration of HPA axis-associated neuroendocrine metabolic programming. Acta Pharmacol Sin. 2013;34(12):1526-34. https:// doi.org/10.1038/aps.2013.171.

33. Wu YM, Luo HW, Kou H, Wen YX, Shen L, Pei LG, et al. Prenatal caffeine exposure induced a lower level of fetal blood leptin mainly via placental mechanism. Toxicol Appl Pharmacol. 2015;289(1):109-16. https://doi.org/1 0.1016/j.taap.2015.09.007.

34. Kliman HJ, Nestler JE, Sermasi E, Sanger JM, Strauss JF III. Purification, characterization, and in vitro differentiation of cytotrophoblasts from human term placentae. Endocrinol. 1986;118(4):1567-82. https://doi.org/10.1210/ endo-118-4-1567.

35. Zhang N, Wang WS, Li WJ, Liu C, Wang Y, Sun K. Reduction of progesterone, estradiol and hCG secretion by perfluorooctane sulfonate via induction of apoptosis in human placental syncytiotrophoblasts. Placenta. 36(5):575-80.

36. Liu F, Soares MJ, Audus KL. Permeability properties of monolayers of the human trophoblast cell line BeWo. Am J Physiol. 1997;273(5 Pt 1):C1596604. https://doi.org/10.1152/ajpcell.1997.273.5.C1596.

37. Didziapetris R, Japertas P, Avdeef A, Petrauskas A. Classification analysis of Pglycoprotein substrate specificity. J Drug Target. 2003;11(7):391-406. https:// doi.org/10.1080/10611860310001648248.

38. Martinec O, Huliciak M, Staud F, Cecka F, Vokral I, Cerveny L. Anti-HIV and anti-hepatitis $C$ virus drugs inhibit P-glycoprotein efflux activity in Caco-2 cells and precision-cut rat and human intestinal slices. Antimicrob Agents Chemother. 2019;63(11):e00910.

39. Hawkins SJ, Crompton LA, Sood A, Saunders M, Boyle NT, Buckley A, et al. Nanoparticle-induced neuronal toxicity across placental barriers is mediated by autophagy and dependent on astrocytes. Nat Nanotechnol. 2018;13(5): 427-33. https://doi.org/10.1038/s41565-018-0085-3.

40. Zhang C, Xu D, Luo H, Lu J, Lu L, Ping J, et al. Prenatal xenobiotic exposure and intrauterine hypothalamus-pituitary-adrenal axis programming alteration. Toxicol. 2014;325:74-84. https://doi.org/10.1016/j.tox.2014.08.015.

41. Berretta E, Guida E, Forni D, Provenzi L. Glucocorticoid receptor gene (NR3C1) methylation during the first thousand days: environmental exposures and developmental outcomes. Neurosci Biobehav Rev. 2021;125: 493-502. https://doi.org/10.1016/j.neubiorev.2021.03.003.

42. Zambrano E, Lomas-Soria C, Nathanielsz PW. Rodent studies of developmental programming and ageing mechanisms: special issue: in utero and early life programming of ageing and disease. Eur J Clin Invest. 2021;1(10):e13631. https://doi.org/10.1111/eci.13631.

43. Chen $Y$, He Z, Chen G, Liu M, Wang H. Prenatal glucocorticoids exposure and fetal adrenal developmental programming. Toxicol. 2019;428:152308. https://doi.org/10.1016/j.tox.2019.152308.

44. Tupova L, Hirschmugl B, Sucha S, Pilarova V, Székely V, Bakos É, et al. Interplay of drug transporters P-glycoprotein (MDR1), MRP1, OATP1A2 and OATP1B3 in passage of maraviroc across human placenta. Biomed Pharmacother. 2020;129:110506. https://doi.org/10.1016/j.biopha.2020.11 0506.

45. Han LW, Gao C, Mao Q. An update on expression and function of p-gp/ abcb1 and bcrp/abcg2 in the placenta and fetus. Expert Opin Drug Metab Toxicol. 2018;14(8):817-29. https://doi.org/10.1080/17425255.2018.1499726.

46. Mark PJ, Augustus S, Lewis JL, Hewitt DP, Waddell BJ. Changes in the placental glucocorticoid barrier during rat pregnancy: impact on placental corticosterone levels and regulation by progesterone. Biol Reprod. 2009; 80(6):1209-15. https://doi.org/10.1095/biolreprod.108.073650.

47. Yakusheva EN, Titov DS. Structure and function of multidrug resistance protein 1. Biochemistry. 2018;83(8):907-29. https://doi.org/10.1134/S00062 97918080047

48. Dunk CE, Pappas JJ, Lye P, Kibschull M, Javam M, Bloise E, et al. Pglycoprotein (P-gp)/ABCB1 plays a functional role in extravillous trophoblast (EVT) invasion and is decreased in the pre-eclamptic placenta. J Cell Mol Med. 2018;22(11):5378-93. https://doi.org/10.1111/jcmm.13810.

49. Wierzejska R, Jarosz M, Wojda B. Caffeine intake during pregnancy and neonatal anthropometric parameters. Nutrients. 2019;11(4):806. https://doi. org/10.3390/nu11040806.

50. Błaszczyk-Bębenek E, Piórecka B, Kopytko M, Chadzińska Z, Jagielski P, Schlegel-Zawadzka M. Evaluation of caffeine consumption among pregnant 
women from southern Poland. Int J Environ Res Public Health. 2018;15(11): 2373. https://doi.org/10.3390/ijerph15112373.

51. Okubo H, Miyake Y, Tanaka K, Sasaki S, Hirota Y. Maternal total caffeine intake, mainly from Japanese and Chinese tea, during pregnancy was associated with risk of preterm birth: the Osaka Maternal and Child Health Study. Nutr Res. 2015;35(4):309-16. https://doi.org/10.1016/j.nutres.2015.02. 009.

52. Christian MS, Brent RL. Teratogen update: evaluation of the reproductive and developmental risks of caffeine. Teratology. 2001;64(1):51-78. https:// doi.org/10.1002/tera.1047.

53. Guilbert JJ. The world health report 2002-reducing risks, promoting healthy life. Educ Health. 2003;16:230.

54. Mark PJ, Waddell BJ. P-glycoprotein restricts access of cortisol and dexamethasone to the glucocorticoid receptor in placental BeWo cells. Endocrinol. 2006;147(11):5147-52. https://doi.org/10.1210/en.2006-0633.

55. Parry S, Zhang J. Multidrug resistance proteins affect drug transmission across the placenta. Am J Obstet Gynecol. 2007;196(5):476.e1-6.

56. Huang J, Zhou S, Ping J, Pan X, Liang G, Xu D, et al. Role of p53-dependent placental apoptosis in the reproductive and developmental toxicities of caffeine in rodents. Clin Exp Pharmacol Physiol. 2012;39(4):357-63. https:// doi.org/10.1111/j.1440-1681.2012.05676.X.

57. Xu D, Luo HW, Hu W, Hu SW, Yuan C, Wang GH, et al. Intrauterine programming mechanism for hypercholesterolemia in prenatal caffeineexposed female adult rat offspring. FASEB J. 2018;32(10):5563-76. https:// doi.org/10.1096/fj.201701557R.

58. Wang L, Myles RC, De Jesus NM, Ohlendorf AKP, Ripplinger CM. Optical mapping of sarcoplasmic reticulum $\mathrm{Ca} 2+$ in the intact heart: ryanodine receptor refractoriness during alternans and fibrillation. Circ Res. 2014;114(9): 1410-21. https://doi.org/10.1161/CIRCRESAHA.114.302505.

59. Venetucci LA, Trafford AW, O'Neill SC, Eisner DA. The sarcoplasmic reticulum and arrhythmogenic calcium release. Cardiovasc Res. 2008;77(2):285-92. https://doi.org/10.1093/cvr/cvm009.

60. Li Y, Lin X, Zhao X, Xie J, JunNan W, Sun T, et al. Ozone (O3) elicits neurotoxicity in spinal cord neurons (SCNs) by inducing ER Ca2 ${ }^{+}$release and activating the CaMKII/MAPK signaling pathway. Toxicol Appl Pharmacol. 2014;280(3):493-501. https://doi.org/10.1016/.ttaap.2014.08.024.

61. Zhang H, Xu H, Ashby CRJ, Assaraf YG, Chen ZS, Liu HM. Chemical molecular-based approach to overcome multidrug resistance in cancer by targeting P-glycoprotein (P-gp). Med Res Rev. 2021;41(1):525-55. https://doi. org/10.1002/med.21739.

62. Sengupta S, Mantha AK, Mitra S, Bhakat KK. Human AP endonuclease (APE1/ Ref-1) and its acetylation regulate YB-1-p300 recruitment and RNA polymerase II loading in the drug-induced activation of multidrug resistance gene MDR1. Oncogene. 2011;30(4):482-93. https://doi.org/10.103 8/onc.2010.435.

63. Li Y, Yan YE, Wang H. Enhancement of placental antioxidative function and P-gp expression by sodium ferulate mediated its protective effect on rat IUGR induced by prenatal tobacco/alcohol exposure. Environ Toxicol Pharmacol. 2011;32(3):465-71. https://doi.org/10.1016/j.etap.2011.08.013.

64. Sekimoto A, Tanaka K, Hashizume Y, Sato E, Sato H, Ikeda T, et al. Tadalafil alleviates preeclampsia and fetal growth restriction in RUPP model of preeclampsia in mice. Biochem Biophys Res Commun. 2020;521(3):769-74. https://doi.org/10.1016/j.bbrc.2019.10.186.

65. Wang Y, Liao S, Guan N, Liu Y, Dong K, Weber W, et al. A versatile genetic control system in mammalian cells and mice responsive to clinically licensed sodium ferulate. Sci Adv. 2020;6:eabb9484.

66. Majewska M, Lipka A, Paukszto L, Jastrzebski JP, Szeszko K, Gowkielewicz M, et al. Placenta transcriptome profiling in intrauterine growth restriction (IUGR). Int J Mol Sci. 2019;20(6):1510.

67. Paquette AG, Houseman EA, Green BB, Lesseur C, Armstrong DA, Lester B, et al. Regions of variable DNA methylation in human placenta associated with newborn neurobehavior. Epigenetics. 2016;11(8):603-13. https://doi. org/10.1080/15592294.2016.1195534.

68. Isaevska E, Moccia C, Asta F, Cibella F, Gagliardi L, Ronfani L, et al. Exposure to ambient air pollution in the first 1000 days of life and alterations in the DNA methylome and telomere length in children: a systematic review. Environ Res. 2021;193:110504. https://doi.org/10.1016/j.envres.2020.110504.

69. Yadama AP, Maiorino E, Carey VJ, McElrath TF, Litonjua AA, Loscalzo J, et al. Early-pregnancy transcriptome signatures of preeclampsia: from peripheral blood to placenta. Sci Rep. 2020;10(1):17029. https://doi.org/10.1038/s41598020-74100-1.
70. O'Grada CM, Morine MJ, Morris C, Ryan M, Dillon ET, Walsh M, et al. PBMCs reflect the immune component of the WAT transcriptome--implications as biomarkers of metabolic health in the postprandial state. Mol Nutr Food Res. 2014;58(4):808-20. https://doi.org/10.1002/mnfr.201300182.

71. Li MX, Zheng HL, Luo Y, He JG, Wang W, Han J, et al. Gene deficiency and pharmacological inhibition of caspase-1 confers resilience to chronic social defeat stress via regulating the stability of surface AMPARs. Mol Psychiatry. 2018;23(3):556-68. https://doi.org/10.1038/mp.2017.76.

\section{Publisher's Note}

Springer Nature remains neutral with regard to jurisdictional claims in published maps and institutional affiliations.

\section{Ready to submit your research? Choose BMC and benefit from:}

- fast, convenient online submission

- thorough peer review by experienced researchers in your field

- rapid publication on acceptance

- support for research data, including large and complex data types

- gold Open Access which fosters wider collaboration and increased citations

- maximum visibility for your research: over $100 \mathrm{M}$ website views per year

At BMC, research is always in progress.

Learn more biomedcentral.com/submissions 